\title{
Population persistence in marine reserve networks: incorporating spatial heterogeneities in larval dispersal
}

\author{
J. Wilson White ${ }^{1,2, *}$, Louis W. Botsford ${ }^{1}$, Alan Hastings ${ }^{3}$, John L. Largier ${ }^{2,3}$ \\ ${ }^{1}$ Department of Wildlife, Fish, and Conservation Biology, University of California, Davis, California 95616, USA \\ ${ }^{2}$ Bodega Marine Laboratory, University of California, Davis, PO Box 247, Bodega Bay, California 94923, USA \\ ${ }^{3}$ Department of Environmental Science and Policy, University of California, Davis, California 95616, USA
}

\begin{abstract}
The relationship between marine reserve design and metapopulation persistence has been analyzed only for cases of spatially homogenous advective-diffusive larval dispersal. However, many coastlines exhibit more complex circulation, such as retention zones in which slower-moving currents shorten dispersal distances and larvae can accumulate. We constructed metapopulation models that incorporated 3 types of spatial variability in dispersal associated with retention zones: (A) reduction of both advective $\left(L_{\mathrm{A}}\right)$ and stochastic $\left(L_{\mathrm{S}}\right)$ length scales of dispersal within the retention zone, (B) reduction of $L_{\mathrm{A}}$ only, and (C) accumulation of larvae in the retention zone, followed by redistribution along the coastline. For each scenario, we examined reserve networks with a range of size and spacing configurations. The scenarios differed in the relative number of self-persistent reserves, i.e. those which can survive in isolation, and network-persistent reserves, i.e. those which rely on connectivity through space and across generations to offset shortfalls in direct self-replenishment. When dispersal was dominated by stochastic movements ( $L_{\mathrm{S}}>L_{\mathrm{A}}$ in scenarios A and B), metapopulations typically consisted of self-persistent reserves. As dispersal became increasingly advective $\left(L_{\mathrm{A}}>\right.$ $L_{\mathrm{S}}$ ), retention aided persistence, and network persistence became more prevalent. Persistence in scenario $\mathrm{C}$ decreased with the amount of redistribution. The specific patterns of persistence depended on the size and number of reserves and demographic parameters, but self-persistence was always more likely for reserves in the retention zone. Thus, placing a reserve in a retention zone to promote population persistence is advisable for all 3 dispersal scenarios.
\end{abstract}

KEY WORDS: Larval dispersal · Dispersal kernel · Headland · Metapopulation · Marine reserve Persistence $\cdot$ Self-recruitment

Resale or republication not permitted without written consent of the publisher

\section{INTRODUCTION}

Knowledge of the patterns of larval dispersal between benthic habitat patches is critical to understanding connectivity and persistence in marine metapopulations (Hastings \& Botsford 2006, Sale et al. 2006, Pineda et al. 2007). Unfortunately, the small size of larvae, the difficulty in tracking individuals, and the complex suite of physical oceanographic forces and larval behaviors that shape larval movement make it difficult to quantify dispersal pathways reliably (Levin 2006, Botsford et al. 2009). Consequently, most theoretical investigations of spatial marine metapopulation dynamics rely on highly simplified assumptions regarding larval dispersal.

Understanding larval dispersal is especially important in one area of considerable recent practical interest: the dynamics of coastal metapopulations of exploited marine fish and invertebrates under spatial management (reviewed by Gerber et al. 2003). Notake marine reserves are an increasingly popular management tool in these systems, and decisions regarding the size and spacing of reserves along a coastline require an understanding of how their place- 
ment influences metapopulation dynamics. Adequate reserve size and placement depends critically on larval dispersal patterns: reserves must be large enough or close enough together to ensure metapopulation persistence (e.g. Botsford et al. 2001, Kaplan et al. 2006, 2009, Walters et al. 2007). In this paper, we consider metapopulations made up of many discrete local populations, and define persistence in a deterministic way: when the metapopulation is near extinction, population density will tend to increase rather than decrease. Our interest is in both overall persistence (Does the metapopulation persist in at least one location?) and the spatial pattern of persistence (Where are the persistent local populations?).

Recent empirical and theoretical results suggest that persistence of a metapopulation in a system of marine reserves depends on 2 mechanisms: (1) selfpersistence of local populations and (2) persistence that depends on connectivity among all or many locations in the network (Botsford et al. 2001, Lipcius et al. 2001, James et al. 2002, Crowder \& Figueira 2006). A single closed population will persist if self-connectivity (the number of larvae that successfully return to the local population) is sufficient to offset post-settlement mortality, a replacement condition we term selfpersistence. By definition, a metapopulation will be persistent if at least one local population is selfpersistent (e.g. as in Van Kirk \& Lewis 1997, Armsworth 2002). However, even when there is not a single self-persistent local population, metapopulations can still persist through multiple, possibly multi-generational replacement pathways produced by dispersing larvae (Hastings \& Botsford 2006). For this 'network effect', the condition for persistence is that shortfalls in self-connectivity to a particular local population must be offset by the exchange of larvae among other local populations within closed reproductive loops. Consequently, an entire network can persist even when the individual local populations are unable to persist independently. In the context of marine reserve design, the potential for network persistence may be an important consideration when it is impossible to ensure that any single reserve will be selfpersistent (Botsford et al. 2001). Moreover, a network of self-persistent reserves may be more resilient to local environmental disturbances than a networkpersistent system would be (Quinn \& Hastings 1987, Allison et al. 2003), although we do not consider the effects of disturbance in the present paper.

For the purpose of evaluating long-term persistence, larval dispersal is commonly described by a kernel, which is the spatial probability distribution for the destination (settlement site) of larvae spawned at a particular location (Largier 2003). In its simplest form, a kernel can be formulated in terms of 2 parameters: an advective length scale $\left(L_{\mathrm{A}}\right)$ describing the mean unidirectional transport of larvae over some time interval, and a stochastic length scale $\left(L_{S}\right)$ describing variation in the mean flow over that time interval as well as smaller-scale fluctuations and turbulence (Largier 2003, Byers \& Pringle 2006). However, obtaining realistic estimates of either parameter remains a daunting task despite recent advances in our understanding of larval dispersal (e.g. Levin 2006). High resolution circulation models have great promise for generating realistic dispersal kernels (Werner et al. 2007), but require many years of development, ground-truthing and evaluation of predictive skill. At present, they are available for only a few regions of the coastal ocean (reviewed by Werner et al. 2007), which has precluded their widespread use in marine reserve design. Emerging results using population genetics and geochemical signatures in otoliths and other tissues also provide some information on the overall spatial scale at which distant populations exchange larvae and the proportion of settling larvae that were produced locally (e.g. Gilg \& Hilbish 2003, Miller et al. 2005, Almany et al. 2007). However, this information is inadequate for parameterizing a dispersal kernel, which requires estimating the proportion of larvae produced at a site that are locally retained as well as the proportions that settle at various distances from that site (Botsford et al. 2009). In many cases, investigators are armed only with an estimate of the mean larval duration for a species and a general sense of the coastal oceanography in a region (Shanks et al. 2003, Shanks \& Eckert 2005).

A few general principles for marine reserve design have been developed despite these constraints on knowledge about dispersal. Several researchers have examined metapopulation persistence using spatially explicit population models of an idealized, onedimensional coastline and assuming a spatially homogenous dispersal kernel that approximates mean flow and diffusion (e.g. Botsford et al. 2001, Gaines et al. 2003, Hastings \& Botsford 2003, Neubert 2003, Kaplan et al. 2006, 2009, Walters et al. 2007). In the simplest case, advection is assumed to be zero (i.e. larvae are distributed symmetrically about the point of release), so that connectivity between habitat units results only from stochastic movement (described by $L_{\mathrm{S}}$ ) and is a decreasing function of distance (Botsford et al. 2001, Hastings \& Botsford 2003, Neubert 2003, Kaplan et al. 2006, 2009). In this scenario, persistence requires that reserves need to meet either one of 2 criteria: (1) reserves must be large enough relative to $L_{\mathrm{S}}$ for lifetime reproduction by individuals in the reserve to provide enough larvae settling within the reserve to replace those individuals (self persistence; Botsford et al. 2001, 2009, Byers \& Pringle 2006); (2) if reserves are small relative to the $L_{\mathrm{S}}$, reserves must cover a specific 
minimum fraction of the coastline that provides sufficient replacement opportunities to sustain a persistent population (network persistence, Botsford et al. 2001, 2009, Hastings \& Botsford 2003). This minimum fraction depends, as before, on the lifetime reproduction of individuals within reserves (Botsford et al. 2001). For models that also include directional larval advection, ensuring persistence typically requires more, larger reserves. In so-called infinite coastline models in which there are no upstream or downstream 'edges', reserve performance is optimized when reserve width or spacing is matched to the length scale of advection, so that larvae spawned in a reserve tend to settle in a reserve (Crowder et al. 2000, Kaplan 2006). Given the uncertainties involved, such a design would not be recommended. On more realistic, non-infinite model coastlines, persistence is even less likely (Gaines et al. 2003). The persistence of populations in advective environments generally depends on the relative magnitude of lifetime reproduction and the ratio of $L_{\mathrm{A}}$ to $L_{\mathrm{S}}$ (Lutscher et al. 2005, Pachepsky et al. 2005, Byers \& Pringle 2006). However, the relationship between this persistence criterion and the optimal design of marine reserves for advective environments has not been explored.

While the basic guidelines derived from nonadvective models (e.g. Botsford et al. 2001) are commonly used in contemporary marine reserve design processes (e.g. CDFG 2008), oceanographic observations and results from circulation models suggest that greater spatial heterogeneity in the shape of dispersal kernels is likely to be the rule rather than the exception (Kaplan \& Largier 2006, Aiken et al. 2007, Siegel et al. 2008), casting doubt on the universality of spatially homogenous model predictions. This situation raises 2 questions: (1) How does spatial heterogeneity in dispersal kernels affect persistence predictions for networks of reserves? (2) How should knowledge about heterogeneity in dispersal patterns be used to guide reserve design and placement?

The numerical circulation model of Aiken et al. (2007), which simulated larval dispersal patterns along the Chilean coastline, provides examples of the types of heterogeneity possible in dispersal kernels. That study region in the Humboldt Current has many features in common with other Eastern Boundary Current systems (e.g. the California, Canary, and Benguela Currents): strong alongshore flows associated with upwelling, which are often interrupted by protruding headlands. These generate upwelling shadows in their leeward embayments, which can act as larval retention zones (Nelson \& Hutchings 1983, Strub et al. 1998, Largier 2004, Largier et al. 2006). A primary finding of the simulations in the Chilean model was that there was considerable heterogeneity in dispersal kernels along the coastline, ranging from strongly advective kernels along most of the coast to kernels with very little net advection in a region characterized by slow mean velocities and the formation of an upwelling shadow. The latter region also experienced high rates of settlement of passive larval particles, primarily from upstream sites (Aiken et al. 2007). While Aiken et al.'s (2007) model lacked some important features of real larvae (e.g. swimming behaviors that would allow them to accumulate in preferred areas in a way that passive drifters cannot), their predictions about circulation and dispersal nonetheless correspond well with observations of surface currents and patterns of larval distribution and settlement in the California Current system. For example, California coastal waters are characterized by strong equatorward flows but include substantial alongshore variability, including regions of slower-moving water in the lee of headlands (Largier et al. 1993, Graham \& Largier 1997, Kaplan et al. 2005, Roughan et al. 2005, Largier et al. 2006).

One feature not evident in a model using passive, neutrally buoyant drifters is the ability of buoyant or swimming larvae to accumulate in retention zones (Largier 2004; see Wing et al. 1998, Mace \& Morgan 2006 for examples from northern California, USA). This accumulation can produce high settlement in the vicinity of the retention zone (Wing et al. 1995a,b, Diehl et al. 2007) and poleward of the retention zone during periodic relaxations of the equatorward flow (Wing et al. 1995a,b, Diehl et al. 2007). In general, it is difficult to determine the origin of larvae within such retention zones, and they could be spawned upstream of, downstream of, or within the zone (Wing et al. 1998), but some information on possible dispersal patterns is available for the relatively well-studied retention zone that forms in the lee of Pt. Reyes, California, during the upwelling season. Drifters released poleward of Pt. Reyes and within the leeward retention zone are entrained and retained, respectively, within the retention zone; drifters within the zone also tend to be transported poleward and up the coast when the alongshore flow relaxes (Largier 2004, Kaplan \& Largier 2006). Additionally, recent results from a numerical circulation model of the northern California coast revealed high levels of retention of buoyant Lagrangian particles (intended to represent fish larvae) in the lee of Pt. Reyes (Petersen et al. 2010). Similar patterns of circulation and retention are evident in observations and models of embayments in other Eastern Boundary Current regions (e.g. Penven et al. 2000).

In light of this evidence, an important next step in improving generic, spatially homogenous models of coastal populations in Eastern Boundary Current systems is to explore the effects of spatial variability in 
dispersal kernels corresponding to the effect of retention zones. For the purposes of this analysis, we define a retention zone as a coastal region where advection is weaker than in the surrounding waters, such that larvae spawned within the retention zone may be retained there and, given appropriate swimming behaviors, larvae spawned elsewhere may be entrained and accumulate there.

It is generally agreed that such heterogeneities in flow, especially areas of larval retention and/or accumulation, should be accounted for in siting marine reserves (Halpern \& Warner 2003, Roberts et al. 2003), but there has been no demonstration of how that would benefit marine reserves. In particular, spatial variability in dispersal distance could accentuate differences between locations that are self-persistent and those that have low self-connectivity and are sustained by a network effect (e.g. Bode et al. 2006, Cowen et al. 2006, reviewed by Gaines et al. 2007). To address the question of marine reserve placement in the presence of flow heterogeneities, we constructed models of spatially distributed populations protected by reserves along a hypothetical coastline containing retention zones. We examined how this dispersal heterogeneity determines where reserves should be placed to ensure population persistence and whether persistence is due to self-connectivity or a network effect. We explored the population dynamics produced by 3 possible heterogeneities in dispersal kernels arising as a result of the retention zones. Examination of these 3 contrasting patterns permitted us to (1) examine the effects on population persistence of different types of spatial heterogeneity in dispersal, and (2) predict the consequences of applying particular management regimes to species with those dispersal patterns.

\section{MATERIALS AND METHODS}

Dispersal scenarios. To explore the effect of retention zones on population persistence within reserve networks, we modeled a metapopulation occupying spatially discrete units of adult habitat strung end-to-end along the coastline. The results are not sensitive to the actual width of this unit so long as the minimum reserve size is greater than the amount of habitat occupied by an adult. This framework is appropriate for any sedentary marine spe- cies in which the spatial scale of adult movement is much less than the size of a single adult habitat unit (Moffitt et al. 2009).

We represented larval dispersal using a Gaussian dispersal kernel (Largier 2003, Siegel et al. 2003) such that the proportion of larvae spawned at location $i$ that disperse to location $j, D_{i j}$ is described by a normal distribution:

$$
D_{i j}=\frac{1}{L_{\mathrm{S}} \sqrt{2 \pi}} \exp \left(-\frac{\left(x_{i j}-L_{\mathrm{A}}\right)^{2}}{2 L_{\mathrm{S}}^{2}}\right)
$$

where $x_{i j}$ is the linear distance between the 2 locations, and $L_{\mathrm{A}}$ and $L_{\mathrm{S}}$ are the advective and stochastic length scales representing the mean displacement and the standard deviation of the dispersal kernel, respectively (Byers \& Pringle 2006; see Table 1 for a summary of symbols and acronyms used in this paper). These length scales will vary among species and location depending on flow statistics and pelagic larval duration (PLD). For example, in a uniform flow field, $L_{\mathrm{A}}=U T$, where $U$ is the mean current velocity and $T$ is the larval duration, and $L_{\mathrm{S}}=\left(\sigma^{2} \tau T\right)^{0.5}$, where $\sigma$ is the standard deviation of the current velocity and $\tau$ is the decorrelation timescale (Siegel et al. 2003, Byers \& Pringle 2006). As such, it is convenient to express the strength of the advective components of flow, relative to the stochastic

Table 1. Symbols used in the present paper

\begin{tabular}{|ll|}
\hline Symbol & Meaning \\
\hline Dispersal & models \\
$\sigma$ & Standard deviation of current velocity \\
$\tau$ & Decorrelation timescale \\
$T$ & Larval duration \\
$U$ & Mean current velocity \\
$X_{i j}$ & Linear distance between cell $i$ and cell $j$ \\
Population & model \\
$C_{i j}$ & Probability of dispersal from $i$ to $j$ and successful recruitment in $j$ \\
$D_{i j}$ & Probability of dispersal from cell $i$ to cell $j$ i element of dispersal \\
& kernel \\
$d$ & Density-independent settler survival \\
$f(S)$ & Settler-recruit survival function \\
FLEP & Fraction of unfished LEP attained by a recruit in a fished area \\
LEP & Mean lifetime egg production of a recruit \\
CRT & Critical replacement threshold \\
$S$ & Settler density \\
$R$ & Recruit density \\
$R_{\mathrm{max}}$ & Maximum density of recruits in one location \\
Length scales & \\
$F_{\mathrm{R}}$ & Fraction of coastline in reserves \\
Pe & Peclet number $\left(=L_{\mathrm{A}} / L_{\mathrm{S}}\right)$ \\
$L_{\mathrm{A}}$ & Advective length scale of dispersal in scenarios A and B \\
$L_{\mathrm{R}}$ & Length scale of flow relaxations in scenario C \\
$L_{\mathrm{S}}$ & Stochastic length scale of dispersal in scenarios A and B \\
$W_{\mathrm{R}}$ & Reserve width \\
$W_{\mathrm{Z}}$ & Retention zone width \\
$p_{\mathrm{Z}}$ & Ratio of length of open coastline to $W_{\mathrm{Z}}$ \\
\hline
\end{tabular}




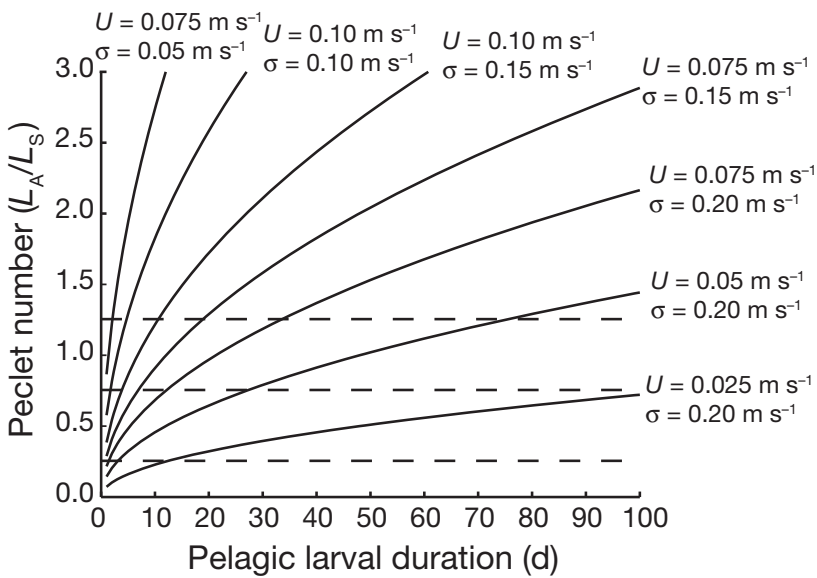

Fig. 1. Peclet number (Pe) describing larval dispersal kernels for a range of flow conditions and pelagic larval durations (PLD). Each curve shows the Pe as a function of PLD for a homogeneous flow with a particular mean $\left(U, \mathrm{~m} \mathrm{~s}^{-1}\right)$ and SD $\left(\sigma, \mathrm{m} \mathrm{s}^{-1}\right)$ of velocity. $\mathrm{Pe}=L_{\mathrm{A}} / L_{\mathrm{S}}$, where $L_{\mathrm{A}}=U T$ and $L_{\mathrm{S}}=$ $\left(\sigma^{2} \tau T\right)^{0.5}, T=$ PLD and $\tau=3 \mathrm{~d}$ (a typical value; Siegel et al. 2003). Dashed lines indicate values of Pe used in the metapopulation model. See Table 1 for definitions

component, using the Peclet number: $\mathrm{Pe}=L_{\mathrm{A}} / L_{\mathrm{S}}$ (Largier 2003; some other authors refer to the square of this ratio as the Peclet number, e.g. Siegel et al. 2003). The relationship between $U, \sigma$, and $T$ is illustrated in Fig. 1 ; note that in these examples, for any combination of $U$ and $\sigma$, the ratio of advective to diffusive effects increases monotonically with $T$ ( $\tau$ was assumed to take the typical value of $3 d_{i}$ Siegel et al. 2003) . The dispersal kernel corresponding to any given combination of these parameters can therefore be represented by a particular value of Pe. To represent the dynamics characteristic of a wide range of species life histories and oceanographic flow conditions, we present modeling results for a range of Pe values.

We intend the one-dimensional dispersal kernels to represent the effects of equatorward alongshore flow such as that present in eastern boundary current systems (e.g. Largier et al. 1993; as used in models by Botsford et al. 2001, Kaplan et al. 2006). We then added spatial heterogeneity to the dispersal kernels in 3 ways that represent different potential effects of a nearshore retention zone (such as that produced in the lee of headlands) on larval dispersal. We emphasize that we are not attempting to model precisely the dynamics of any particular species or geographic location, but rather to capture the key features of several generic dispersal types.

First, we consider the case in which larvae spawned in the retention zone have the same Pe as larval spawned along the open coast (i.e. same ratio of $L_{\mathrm{A}} / L_{\mathrm{S}}$ ) but both $L_{\mathrm{A}}$ and $L_{\mathrm{S}}$ are reduced in magnitude by onehalf. This scenario represents the pattern evident in
Aiken et al.'s (2007) results that the mean and standard deviation of dispersal kernels are generally correlated. We refer to this as dispersal scenario A henceforth (Fig. 2a).

Second, we consider the case (dispersal scenario B) in which larvae spawned within the retention zone have a kernel with $L_{\mathrm{A}}=0$ but $L_{\mathrm{S}}$ has the same value as that experienced by larvae spawned along the open
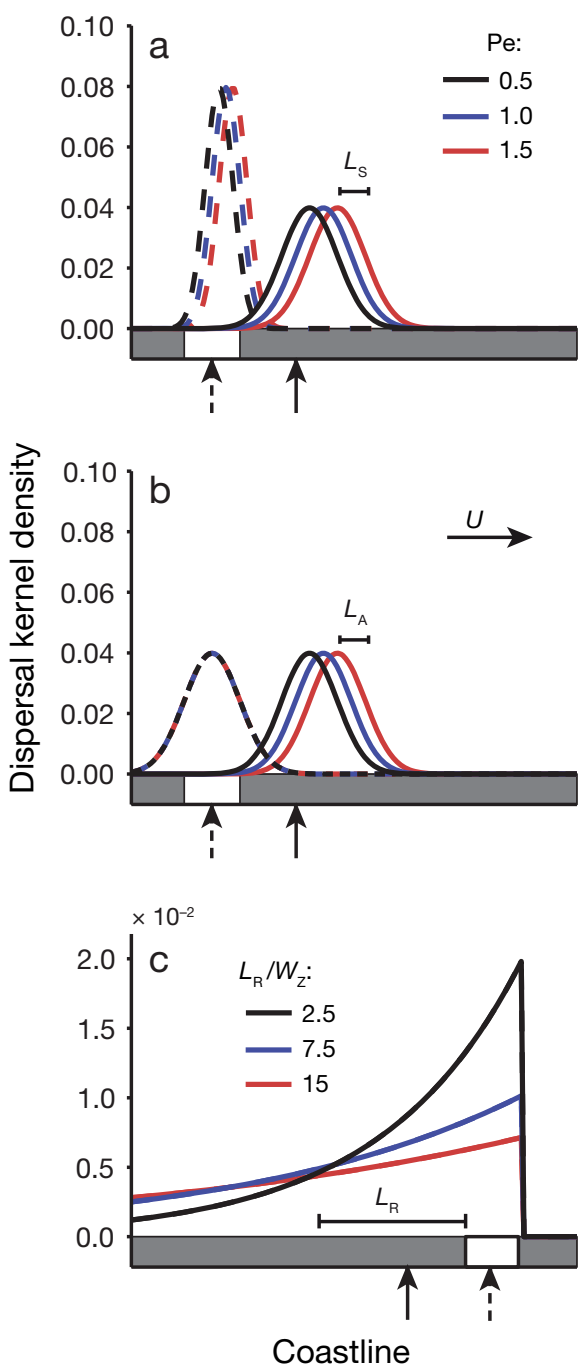

Fig. 2. Representative dispersal kernels for larvae spawned inside the retention zone (dashed curves) and on the open coast (solid curves). Dashed and solid arrows: release points. White boxes: retention zones (with width $W_{\mathrm{Z}}$ ). Gray boxes: open coast regions (only a portion of the model coastline is shown). (a-c) Results for the corresponding dispersal scenarios. $(\mathrm{a}, \mathrm{b})$ kernels have $\mathrm{Pe}=0.5,1.0$, and 1.5 (indicated by gray shading; in $\mathrm{b}$, larvae spawned in retention zone have overlapping kernels for each value of Pe). Scale bar: length scale $L_{\mathrm{S}}$ or $L_{\mathrm{A}}$ for the open-coast kernels. Horizontal arrow in b: intended direction of the prevailing current. (c) Kernels have $L_{\mathrm{R}}=2.5 \mathrm{~W}_{\mathrm{Z}}, 7.5 \mathrm{~W}_{\mathrm{Z}}, 15 \mathrm{~W}_{\mathrm{Z}}$ spatial units (indicated by gray shading); scale bar shows $L_{\mathrm{R}}=2.5 W_{\mathrm{Z}}$. See Table 1 for definitions 
coast, resulting in $\mathrm{Pe}=0$ for larvae in the retention zone (Fig. 2b). This produces a kernel with its mode at the point of release, similar to Aiken et al.'s (2007) prediction for larvae spawned within a Chilean retention zone.

Third, we consider an altogether different type of kernel (dispersal scenario C) which is not resolved by models of passive drifters but which reflects the leading hypothesis regarding the dispersal of invertebrate larvae in the vicinity of northern California retention zones (Botsford 2001, Largier 2004, Diehl et al. 2007). In this scenario, larvae spawned in the region between retention zones are transported equatorward towards the downstream retention zone, where swimming behaviors allow them to accumulate in the zone along with larvae spawned in the zone and retained there (Wing et al. 1998). Settlement is highest within the retention zone, but periodic flow relaxations also distribute accumulated larvae along the coast upstream of the retention zone (Wing et al. 1995a,b, 2003, Diehl et al. 2007). We represented this pattern by assuming that the dispersal kernel is identical for each release point within a region of the coast stretching from the equatorward edge of one retention zone to the equatorward edge of the next retention zone. This kernel follows a negative exponential distribution with its maximum value at the retention zone and scale parameter $L_{R}$ (intended to represent the length scale of flow relaxations):

$$
D_{i j}=\frac{1}{2 L_{\mathrm{R}}} \exp \left(\frac{-x_{j}}{L_{\mathrm{R}}}\right)
$$

where $x_{j}$ is the distance from the equatorward edge of the retention zone to location $j$. The mean dispersal distance for this kernel is: $\sqrt{2} L_{\mathrm{R}}$. In other words, larvae spawned at every point along the coast have an identical high probability of settling within the retention zone, and the probability of settlement declines poleward (Fig. 2c). Unlike the Gaussian dispersal kernels in scenarios A and B, this kernel is phenomenological and not derived from a fluid dynamics argument, but it does re-create a type of dispersal pattern hypothesized by multiple authors (Carr \& Reed 1993, Botsford 2001, Diehl et al. 2007) and supported by evidence from drifter studies (Largier 2004) and numerical circulation models (Petersen et al. 2010). The negative exponential functional form for this scenario was chosen to match the exponentially decaying pattern in larval settlement poleward of headlands described by Diehl et al. (2007). Just as we varied Pe in scenarios A and B, here we vary the length scale $L_{R}$ to reflect possible variations in the shape of this kernel (Fig. 2c). As $L_{\mathrm{R}}$ increases, this kernel approaches a completely homogenous redistribution of larvae along the coastline (i.e. a larval pool).
These dispersal scenarios represent 3 distinct and fundamental ways that spatial heterogeneity in larval dispersal might arise. In the absence of a full circulation model, the extent of knowledge about dispersal in a region might be limited to the likelihood that one or more of these general types of heterogeneity is present.

Spatial configuration of coastline and reserves. For each of the 3 dispersal scenarios, we examined the patterns of metapopulation persistence that would result from implementation of marine reserve networks with a variety of configurations. We evaluated spatial configurations in which reserves of the same width were spaced periodically, and the habitat was homogenous. The configuration of reserves within the habitat domain could thus be described by 2 parameters: reserve width $\left(W_{\mathrm{R}}\right)$ and the fraction of the coastline in reserves $\left(F_{\mathrm{R}}\right)$ (e.g. as in Fig. 2 of Botsford et al. 2001). For a coastline containing retention zones, the reserve configuration is further defined by specifying whether reserves are placed in the retention zone.

The coastline itself consisted of multiple repeating units. Each unit was composed of a retention zone (of width $W_{\mathrm{Z}}$ ) and the stretch of open coastline upcurrent of the retention zone (of width $p_{\mathrm{Z}} W_{\mathrm{Z}}$, where $p_{\mathrm{Z}}$ is a constant). Thus, each unit was completely described by 5 parameters: $W_{\mathrm{R}}, F_{\mathrm{R}}, W_{\mathrm{Z}}, p_{\mathrm{Z}}$, and whether the retention zone contained a reserve (Fig. 3). We expressed the length scales $W_{\mathrm{R}}$ and $W_{\mathrm{Z}}$ in terms of the dispersal length scale $L_{S}$. For the results presented here, we kept $L_{\mathrm{S}}$ constant and varied $L_{\mathrm{A}}$ to obtain different values of Pe for scenarios A and B. This nondimensionalized the results, which depended not on the actual value of $W_{R}$ and $W_{\mathrm{Z}}$ but rather on their value relative to Pe (and $L_{\mathrm{A}}$ ). We also set $W_{\mathrm{Z}}=2 L_{\mathrm{S}}$ in all cases. Although $L_{\mathrm{S}}$ does not appear in the dispersal kernel for scenario $C$, we used the same coastline configurations in that scenario as in $\mathrm{A}$ and $\mathrm{B}$, and simply expressed $L_{\mathrm{R}}$ relative to $W_{\mathrm{Z}}$. Exploratory model runs confirmed that the results of all 3 dispersal scenarios were insensitive to the values chosen for $W_{Z}$ and $L_{S}$. The model results were sensitive to the value of $p_{Z}$ : for very large values of $p_{Z}$, the retention zone becomes very small relative to the rest of the coastline, and model results approach those from models without a retention zone (i.e. Fig. 2 in Botsford et al. 2001). For very small $p_{\mathrm{Z}}$ values, the retention zone dominated the coastline. We present results for $p_{Z}=20$, reflecting the case in which the retention zone occupies $5 \%$ of the coastline unit.

We simulated coastlines with 5 consecutive repeating units. Using this number of repeats minimizes edge effects in that it does not matter whether the retention zone is on the upcurrent or downcurrent edge of the repeating unit. However, this setup differs from models with infinite coastlines in that it is possible that the 


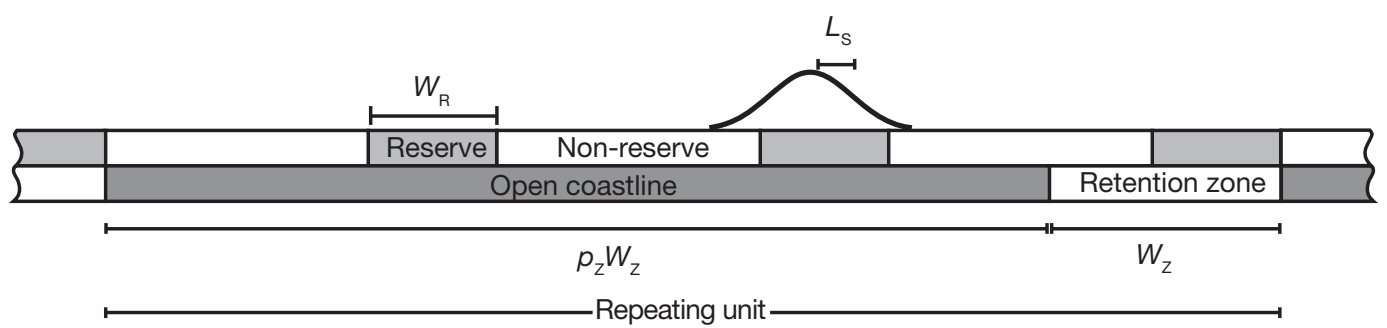

Fig. 3. One-dimensional model coastline. Each point along the coastline is defined by being in or out of a reserve and in or out of an oceanographic retention zone. Top row: evenly spaced gray boxes = reserves of width $W_{\mathrm{R}}$ and covering a given fraction of the coastline; white spaces $=$ open to fishing. Bottom row: evenly spaced white boxes $=$ retention zones of width $W_{\mathrm{Z}}$ dark gray spaces $=$ open coastline regions of width $p_{\mathrm{Z}} W_{\mathrm{Z}}$ (where $p_{\mathrm{Z}}=$ constant). Only 1 repeating unit of coastline is shown along with the edges of the 2 adjacent repeating units. The entire model coastline consists of 5 such units. See Table 1 for definitions

metapopulation will not persist in the face of strong advection (Gaines et al. 2003, Byers \& Pringle 2006).

Population model. The equilibrium value of recruitment at point $i$ along the coast can be expressed as a sum of larval production at other points along the coast and the dispersal from those points to $i$ :

$$
\begin{aligned}
R_{i} & =f\left(S_{i}\right) \\
S_{i} & =\sum_{j} D_{j i} \operatorname{LEP}_{j} R_{j}
\end{aligned}
$$

where $\mathrm{LEP}_{j}$ is the mean lifetime egg production of a recruit at $j$, and $f(S)$ is the relationship between settlement, $S$, and recruitment, $R$. The value of LEP reflects the local pattern of age-dependent post-recruitment survivorship and fecundity at age. Fishing will reduce natural LEP to a fraction (FLEP) of the unfished maximum $(0<$ FLEP $<1)$. FLEP is calculated from local survival (including fishing effects) and the fecundityvs.-age relationship (Kaplan et al. 2006). LEP and FLEP are equivalent to eggs-per-recruit (EPR) and spawning potential ratio (SPR), respectively, in the fisheries literature (Goodyear 1993).

If Eq. (4) is rescaled so that $R$ and $S$ are expressed as fractions of their unfished maximum values, the population dynamics can be expressed as:

$$
\begin{aligned}
R_{i} & =f\left(S_{i}\right) \\
S_{i} & =\sum_{j} D_{j i} \operatorname{FLEP}_{j} R_{j}
\end{aligned}
$$

Here $f\left(S_{i}\right)$ represents pre- and post-settlement survival of larvae settling and recruiting into the adult population at $i$, and $\mathrm{FLEP}_{j}$ summarizes the relevant post-recruitment demographic processes (growth, mortality, maturity, fecundity) at $j$. Together these equations summarize the minimal amount of life history information needed to assess population persistence at equilibrium (i.e. survival and fecundity at age; Botsford et al. 2001, Kaplan et al. 2006).

The function $f(S)$ represents the nonlinear dependence of post-settlement recruitment on abundance of settling larvae (a reasonable assumption for many habitat-limited marine species; Caley et al. 1996). We used a 'hockey stick' settler-recruit relationship (Barrowman \& Myers 2000, Kaplan et al. 2006) in which settlers have constant, density independent survival ( $\delta$ ) to the recruit stage, but the density of surviving recruits is constrained to a maximum $R_{\max }$. That is, $R_{i}=$ $\delta S_{i}$ for $\delta S_{i} \leq R_{\max }$ and $R_{i}=R_{\max }$ for $\delta S_{i}>R_{\max }$.

The inverse of the density-independent survival $\delta$ can also be thought of as the critical replacement threshold (CRT). In a nonspatial version of Eq. (5) in which there is only one closed population $\left(D_{11}=1\right)$, the population will only persist if FLEP > CRT. In this way, FLEP is similar to the individual lifetime replacement rate in linear population dynamics (Caswell 2001). Just as a linear (i.e. not density dependent), nonspatial population will persist if each individual replaces itself within its lifetime $\left(R_{0}>1\right)$, for a single, islolated, agestructured population with density-dependent recruitment, FLEP must exceed the CRT, at which point each adult produces just enough larvae such that at least 1 survives the planktonic larval stage, settles, and successfully recruits into the reproductive population (Sissenwine \& Shepherd 1987). A similar relationship holds in our spatial model (Eq. 5): if $\mathrm{FLEP}_{i}<\mathrm{CRT}$ at all locations $i$, the population will not replace itself, and hence would decline to extinction (Kaplan et al. 2006). If FLEP $_{i}$ exceeded the CRT at all locations, the habitat is saturated with $R_{\max }$ recruits and the population would persist. When reserves were included in the model, we assumed that FLEP $_{i}$ varied over space, with $\mathrm{FLEP}_{i}=1$ (unfished) inside reserves and $\mathrm{FLEP}_{i}<1$ outside reserves, but with the same hockey-stick settlerrecruit relationship at all locations. The saturated level of recruitment $R_{\max }$ has essentially arbitrary units, so we assumed $R_{\max }=1$.

Rather than simulate the full transient population dynamics to determine persistence, we focused on the effect of dispersal patterns and reserve configurations on the equilibrium spatial distribution of settlers and recruits using the computationally efficient dispersal per recruit (DPR) method of Kaplan et al. (2006) to 
solve Eq. (5). In brief, this technique involves initially seeding the domain with the maximum density of recruits $\left(R_{i}=R_{\max }\right)$ at all locations, then iterating Eq. (5) until the distribution of $R_{i}$ along the coastline reaches a steady state. A consequence of using a hockey-stick form for $f(S)$ is that it is possible to characterize the spatial distribution of the metapopulation at equilibrium by the proportion of locations that are saturated with recruits $\left(R_{i}=R_{\max }\right)$. At these locations, the percapita replacement rate is unity (each recruit is replaced within its lifetime). In this model, at least one location must be saturated for the metapopulation to persist, and as a greater proportion is saturated, the metapopulation approaches the unfished state. Representing persistence in terms of proportional recruit saturation is a convenience afforded by the hockey-stick function, but any other saturating recruitment function (e.g. Beverton-Holt) with the same initial slope $\delta$ at the origin would produce exactly the same relationship between the spatial distribution of FLEP $_{i}$ and metapopulation persistence.

In addition to calculating the proportional recruit saturation for each model run, we also determined whether persistent reserve networks consisted of 0,1 , or $>1$ self-persistent reserves by following the rationale of Hastings \& Botsford (2006). Self persistence requires that the fraction of larvae spawned over the lifetime of an individual within a reserve and subsequently recruiting to that same reserve is sufficient to completely replace that individual population in that reserve without any larval supply from other locations. Mathematically, this requirement is evaluated by considering the case of near-zero population densities in all locations (thus ignoring all density dependence) and constructing a population projection matrix $\mathbf{C}_{\text {, where }} \mathrm{C}_{j i}=$ $\delta \mathrm{FLEP}_{j} D_{j i}$. Here each entry $\mathrm{C}_{j i}$ describes the probability of successful recruitment of offspring from $j$ into $i$. For a network of reserves, each reserve corresponds to a principal minor submatrix of $\mathbf{C}$. If the dominant eigenvalue of that submatrix is $>1$, densities in that reserve would increase without outside input, and we counted that reserve as self-persistent. Even if no reserve was self-persistent, the entire network persisted if the dominant eigenvalue of $\mathbf{C}$ was $>1$, a condition that was met whenever the DPR approach predicted that $>0 \%$ of the coastline was saturated with recruits. This latter persistence criterion is effectively equivalent to that proposed by Lutscher et al. (2005) for population persistence in a semi-infinite linear domain.

By describing population status in terms of FLEP, and its value relative to the CRT, it was possible to examine the consequences of different dispersal life histories independent of any differences in postdispersal life history. In other words, we compared populations that were fished at a particular FLEP, and our results depended only on the magnitude of FLEP relative to the CRT, not on the specific life history parameters used to calculate FLEP. Because we were considering long-term equilibrium solutions, not transient responses to reserve implementation, we did allow total fishing effort to be conserved as total reserve area increased. In other words, runs with higher reserve area and the same value of FLEP outside of reserves represented lower total removals by fishing.

For many fished species, the CRT appears to occur near FLEP $\leq 0.35$ (i.e. LEP is $35 \%$ of the unfished maximum; Mace \& Sissenwine 1993, Dorn 2002). In our analysis we focused on results obtained using CRT = 0.35 and $\mathrm{FLEP}_{i}=0$ outside of reserves, similar to the approach of Botsford et al. (2001). However, noting that population persistence in advective environments typically has a nonlinear dependence on reproductive output (Lutscher et al. 2005, Pachepsky et al. 2005, Byers \& Pringle 2006), we also explored the sensitivity of our results to variation in the CRT and on the value of $\mathrm{FLEP}_{i}$ outside of reserves.

\section{RESULTS}

The basic effect of increasing reserve size or the number of reserves on the spatial distributions of larval settlement was the same for all 3 dispersal scenarios whenever FLEP < CRT: as more reserve area was added, total larval production increased and more larvae spilled over from reserves to non-reserve habitat. We illustrate the general model behavior by comparing the equilibrium spatial distributions of larval settlement for each dispersal scenario using CRT $=0.35$ and FLEP $=0$ outside reserves, under several representative reserve configurations in which a reserve was placed in the retention zone (Fig. 4). This figure indicates the positions of reserves and retention zones for the middle portion of the model coastline (one full repeating unit is shown, along with the edges of its neighbors). The equilibrium density of settlers at each location is indicated by the curve; the resulting density of recruits is obtained by multiplying the settler density by $1 / 0.35$. Thus, when settler density exceeds the dashed line at 0.35 , recruit density $=R_{\max }$, and that location is said to be saturated with recruits. Recall that $\geq 1$ location must be saturated at equilibrium for the metapopulation to persist.

When $\mathrm{Pe}=0.75, W_{\mathrm{R}}$ is equal to $110 \%$ of $L_{\mathrm{S}}$ and $10 \%$ of $F_{\mathrm{R} i}$ only the reserve in the retention zone sustained a persistent local population in both dispersal scenarios A and B (Fig. 4a,b). In both cases, the reserve in the retention zone was also self-persistent. A similar result was obtained when $L_{\mathrm{R}}$ equaled $750 \%$ of $W_{\mathrm{Z}}$ in dispersal scenario C (Fig. 4c). 
Dispersal scenario A
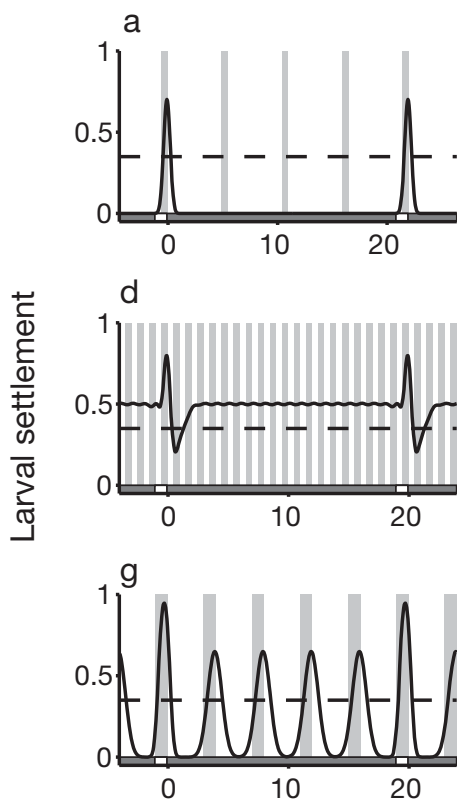

Dispersal scenario B

b
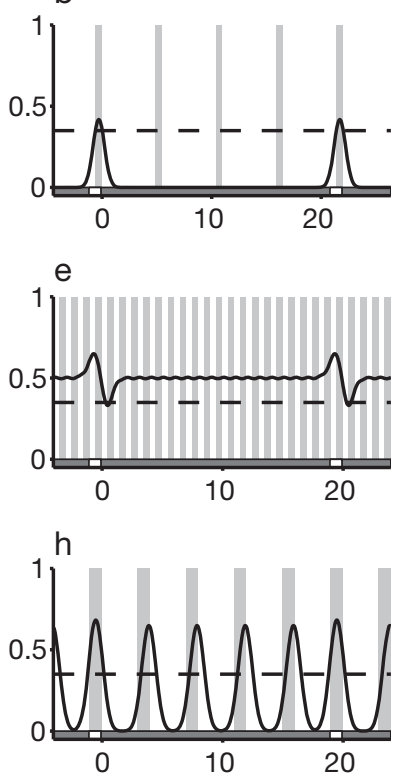

Dispersal scenario C
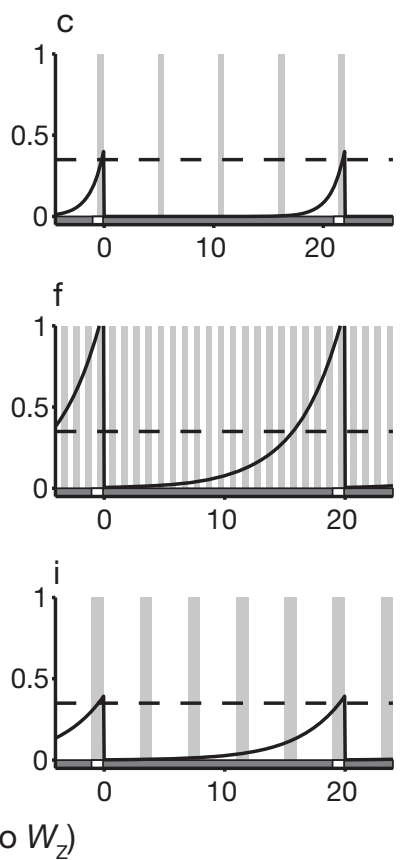

Fig. 4. Spatial pattern of larval settlement at equilibrium for representative examples from each dispersal scenario. Horizontal gray bar: middle repeating unit of the coastline with white segments demarcating the retention zones (as in Fig. 2); Vertical grey bars: position of reserves. Curve: equilibrium density of settlers as a proportion of the unfished maximum. Horizontal dashed line: critical replacement threshold (1/slope of the settler-recruit function); locations with settler densities above this line have maximum density of recruits $\left(R_{\mathrm{max}}\right)$ and the adult population in those locations is fully replaced. In panels a-c, reserves are just wide enough for the reserve in the embayment to be self-persistent $\left(W_{\mathrm{R}}=1.1 L_{\mathrm{S}}\right.$, for Pe $=0.75$ in a \& $\mathrm{b} ; L_{\mathrm{W}}=2.5 W_{\mathrm{Z}}$ in $\left.\mathrm{c}\right)$ and $10 \%$ of the coastline is in reserves $\left(F_{\mathrm{R}}=0.1\right)$. $(\mathrm{d}-\mathrm{f})$ : reserves are smaller $\left(W_{\mathrm{R}}=0.5 L_{\mathrm{S}}\right)$ but cover $50 \%$ of the coastline $\left(F_{\mathrm{R}}=0.5\right)$. $(\mathrm{g}-\mathrm{i})$ : reserves are larger $\left(W_{\mathrm{R}}=2 L_{\mathrm{S}}\right)$ but cover less of the coastline $\left(F_{\mathrm{R}}=0.125\right)$. $(\mathrm{d}-\mathrm{i})$ : Pe $=0.75$ and $L_{\mathrm{R}}=7.5 W_{\mathrm{Z}}$. In all panels, FLEP $=0$ outside reserves, FLEP $=1$ inside reserves, and $C R T=0.35$. See Table 1 for definitions

When reserves were smaller in size $\left(W_{\mathrm{R}}=0.5 L_{\mathrm{S}}\right)$ but covered a greater fraction of the coastline $\left(F_{\mathrm{R}}=50 \%\right)$, much more of the coastline was saturated with recruits in all 3 dispersal scenarios (Fig. 4d-f). In this case, no individual reserve was large enough to be selfpersistent, so the metapopulation persisted via a network effect. That is, because each reserve was so small, most locally produced larvae settled outside of their natal reserve. No reserve received enough settlement of locally-produced larvae to be self-persistent, but neighboring reserves exchanged sufficient larvae for the entire reserve network to support a persistent population. The entire coastline was not saturated with recruits, however, as there was a deficit of settlers just downstream of the retention zone in scenarios A and B. This occured because larvae advected downstream from those locations were not replaced by larvae arriving from upstream sources, since larvae spawned inside the retention zone have reduced dispersal distances. In scenario $\mathrm{C}$, locations furthest upstream of the retention zone received very little larval supply due to the shape of the dispersal kernel.
In the final example, $W_{\mathrm{R}}$ was doubled but $F_{\mathrm{R}}$ was halved (Fig. 4g-i). In this example, all reserves are wide enough to be self-persistent in dispersal scenarios $\mathrm{A}$ and $\mathrm{B}$, but fished regions between reserves receive very little larval supply. That is, the metapopulation persisted due to the self-persistence of individual reserves, and non-self-persistent regions between reserves did not experience a network effect because reserves were spaced too widely. For the same reserve configuration in dispersal scenario $\mathrm{C}$, only reserves in the retention zones were saturated with recruits; these reserves were also self-persistent.

To represent the effects of a wider range of reserve configurations on population persistence, we summarized each model run in terms of the fraction of the coastline that was saturated with recruits as we varied $W_{\mathrm{R}}$ and $F_{\mathrm{R}}$. To aid in the interpretation of this type of result, we first present the results of model runs in which there is no retention zone, so larvae spawned in all locations have the same value of Pe (Fig. 5). This is very similar to the models analyzed by Botsford et al. (2001; compare our Fig. 5 to their Fig. 2). For each panel in 

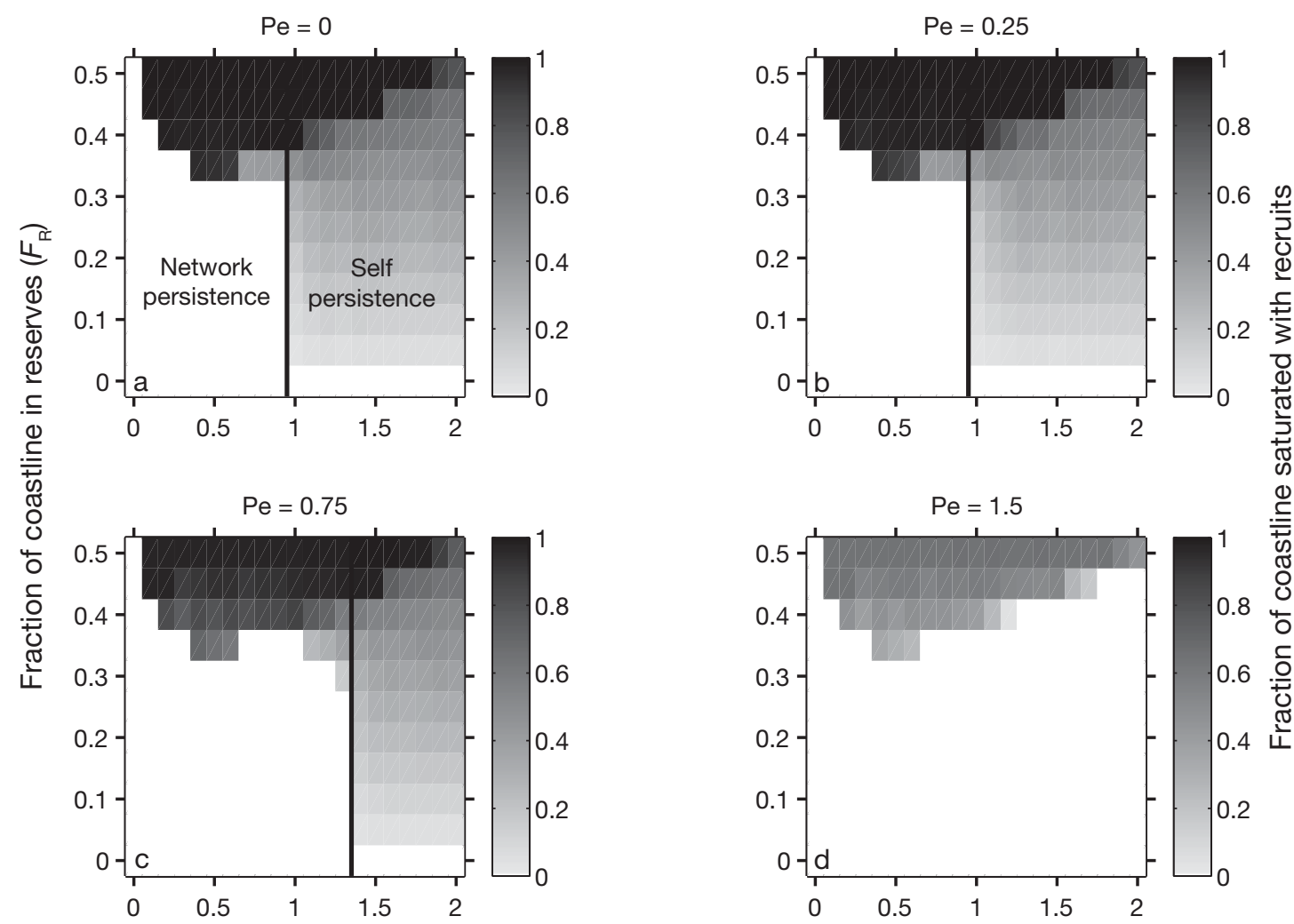

Reserve width $\left(R_{\mathrm{w}}\right.$; relative to $\left.L_{\mathrm{s}}\right)$

Fig. 5. Mean fraction of the coastline saturated with recruits under a scenario with no retention zone. Pixels: reserve network with a particular combination of $W_{\mathrm{R}}$ and $F_{\mathrm{R} i}$ pixel shading: recruit saturation at equilibrium; white areas: non-persistent metapopulations. (a-c) Black vertical lines: minimum $W_{\mathrm{R}}$ for all reserves to be self-persistent. Reserve configurations supporting persistent metapopulations in regions to the left of the black line represent cases of network persistence, in which no individual reserve is self-persistent (this is the case for all persistent reserve configurations in panel d). Peclet number (Pe) range: 0-1.5. In these model runs, $\mathrm{CRT}=0.35, \mathrm{FLEP}=1$ inside reserves and FLEP $=0$ outside reserves. See Table 1 for definitions

Fig. 5, the shading of each pixel indicates the equilibrium fraction of the coastline saturated with recruits for that particular combination of $W_{\mathrm{R}}$ and $F_{\mathrm{R}}$. Note that for a given value of $W_{\mathrm{R}}$ increasing $F_{\mathrm{R}}$ adds additional reserves of that width to the coastline. For a given $F_{R}$, increasing $W_{\mathrm{R}}$ causes there to be fewer, wider reserves. The 4 panels show results for increasing values of $\mathrm{Pe}$, from no advection $(\mathrm{Pe}=0)$ to relatively higher advection $(\mathrm{Pe}=1.5)$. In these model runs, FLEP $=0$ outside reserves, so the metapopulation does not persist for low values of either $W_{\mathrm{R}}$ or $F_{\mathrm{R}}$. As either $W_{\mathrm{R}}$ or $F_{\mathrm{R}}$ increases, persistence becomes possible and some fraction of the coastline is saturated with recruits. For low values of $F_{\mathrm{R}}$ (i.e. a low fraction of coastline in reserves), persistence first becomes possible when reserves are wide enough to support a self-persistent population, a value of $W_{\mathrm{R}}$ denoted by the vertical black line. To the right of this line, all reserves are self-persistent; to the left of the line, the metapopulation persists via network effects only if $F_{\mathrm{R}}$ is large enough to support a network effect (note that self-persistence is solely a function of $W_{\mathrm{R}}$ not
$\left.F_{\mathrm{R}}\right)$. As Pe increases, reserves must be wider to be selfpersistent, so the self-persistence boundary shifts to the right. We did not simulate reserves wide enough to be self-persistent for $\mathrm{Pe}=1.5$ or greater. By contrast, $\mathrm{Pe}$ has no apparent effect on the minimum value of $F_{\mathrm{R}}$ necessary for network persistence when $W_{\mathrm{R}}$ is less than the self-persistence threshold. Additionally, metapopulations that persisted via network effects (high $F_{\mathrm{R}}$ low $W_{\mathrm{R}}$ ) typically had nearly the entire coastline saturated with recruits because the many small reserves export most locally-produced larvae, supplying non-reserve regions, whereas when metapopulations consisted of few self-persistent reserves (low $F_{\mathrm{R}}$, high $W_{\mathrm{R}}$ ), only the portions of the coastline within or adjacent to the (relatively large) reserves were saturated with recruits. On coastlines with high $F_{\mathrm{R}}$ and $W_{\mathrm{R}}$, the fraction saturated is reduced somewhat because the reserves are larger and spaced further apart than when $W_{\mathrm{R}}$ is lower, leaving gaps in larval supply between the reserves.

Figs. 6 to 8 display summary statistics similar to those in Fig. 5 for each of the dispersal scenarios (with reten- 
$\mathrm{Pe}=0.25$

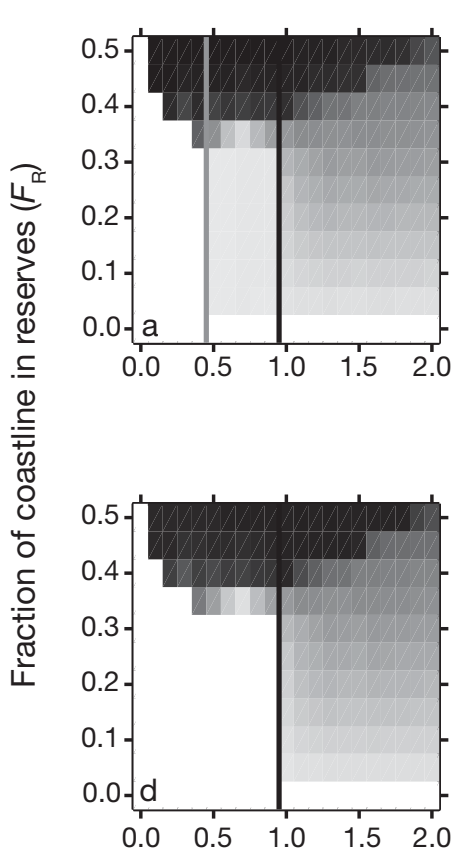

$\mathrm{Pe}=0.75$

Reserve in retention zone

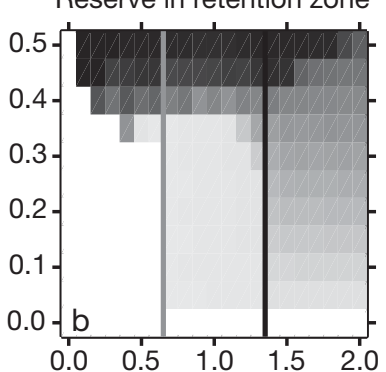

No reserve in retention zone

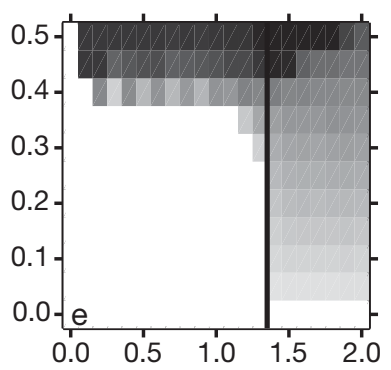

$\mathrm{Pe}=1.5$

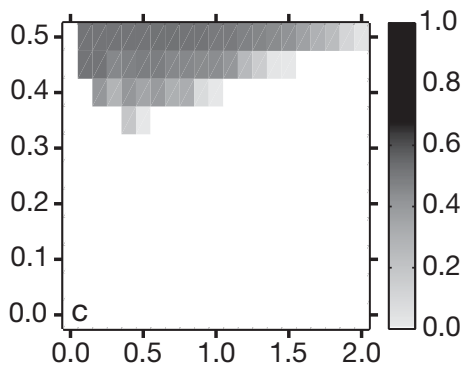

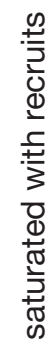

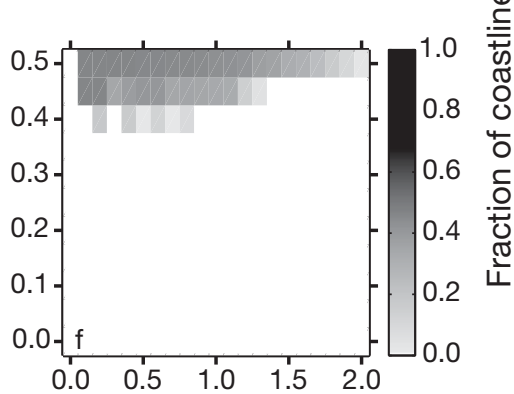

Reserve width $\left(R_{w}\right.$; relative to $\left.L_{S}\right)$

Fig. 6. Mean fraction of the coastline saturated with recruits under different reserve configurations for dispersal scenario A. Pixels: reserve network with a particular combination of $W_{\mathrm{R}}$ and $F_{\mathrm{R} i}$ pixel shading: recruit saturation at equilibrium; white areas: non-persistent metapopulations. In panels a-c, reserves are sited in retention zones; in $d-f$, they are not. Vertical lines: gray, minimum reserve width $\left(W_{R}\right)$ for the reserves in the retention zones to be self-persistent; black, minimum $W_{R}$ for all reserves to be self-persistent. Reserve configurations supporting persistent metapopulations in regions to the left of either line or in panels without vertical lines represent cases of network persistence, in which no individual reserve is self-persistent. Peclet number (Pe) was either $0.25(\mathrm{a}, \mathrm{d}), 0.75(\mathrm{~b}, \mathrm{e})$, or $1.5(\mathrm{c}, \mathrm{f})$. Larvae spawned inside the retention zone had same Pe as larvae spawned on the open coast but both $L_{\mathrm{A}}$ and $L_{\mathrm{S}}$ were reduced by $50 \%$. In these model runs, CRT $=0.35, \mathrm{FLEP}=1$ inside reserves, FLEP $=0$ outside reserves. See Table 1 for definitions

tion zones) for 3 representative values of Pe and $L_{\mathrm{R}}$ and assuming FLEP $=0$ outside reserves and CRT $=0.35$. In Figs. 6 to 8 , the black line has the same meaning as in Fig. 5 (to the right of the line, all reserves on the coastline are self-persistent). In some panels there is also a gray line which demarcates reserve configurations in which only the reserves in the retention zones were self-persistent. For some dispersal scenarios, reserves were never wide enough to be self-persistent when FLEP $=0$ (e.g. Fig. 6c), although we only considered widths up to $2 L_{\mathrm{S}}$.

The summarized results for dispersal scenario A (Fig. 6) and B (Fig. 7) were largely similar to each other and to the no-retention-zone case shown in Fig. 5. As $W_{\mathrm{R}}$ increased for a constant, low $F_{\mathrm{R}}(<0.3)$ and low Pe values $(\mathrm{Pe}<1)$, the fraction of the coastline saturated with recruits increased, but there was little spillover into non-reserve areas and the saturated fraction remained low even when all reserves were wide enough to be self-persistent (e.g. Figs. $6 \mathrm{~b} \& 7 \mathrm{~b}$ ). When there were no reserves in the retention zones, the results were very similar to those from the example without a retention zone (Fig. 5): for low $F_{R}$, reserves had to be wide enough for all reserves to be selfpersistent in order for the metapopulation to persist at all (Figs. 6d,e \& 7d,e). When there were reserves in the retention zones, the metapopulation became persistent (and the reserves in the retention zones became selfpersistent) with much smaller reserves (compare Figs. 6a and d, 6b and e, and $7 \mathrm{~b}$ and e). This occurred because local populations in the retention zones had dispersal kernels with Pe values lower than those on the open coast, so the retention zones experienced much higher larval retention. The exception to this general pattern was for $\mathrm{Pe}=0.25$ in dispersal scenario $\mathrm{B}_{i}$ in this case, there was so little advection that reserves inside and outside of the retention zone had very similar dispersal kernels and effectively the same minimum width for self-persistence (Fig. 7a,d).

When reserves were held at a constant, small width (less than the threshold for self-persistence), increasing $F_{\mathrm{R}}$ produced a steep transition from non- 

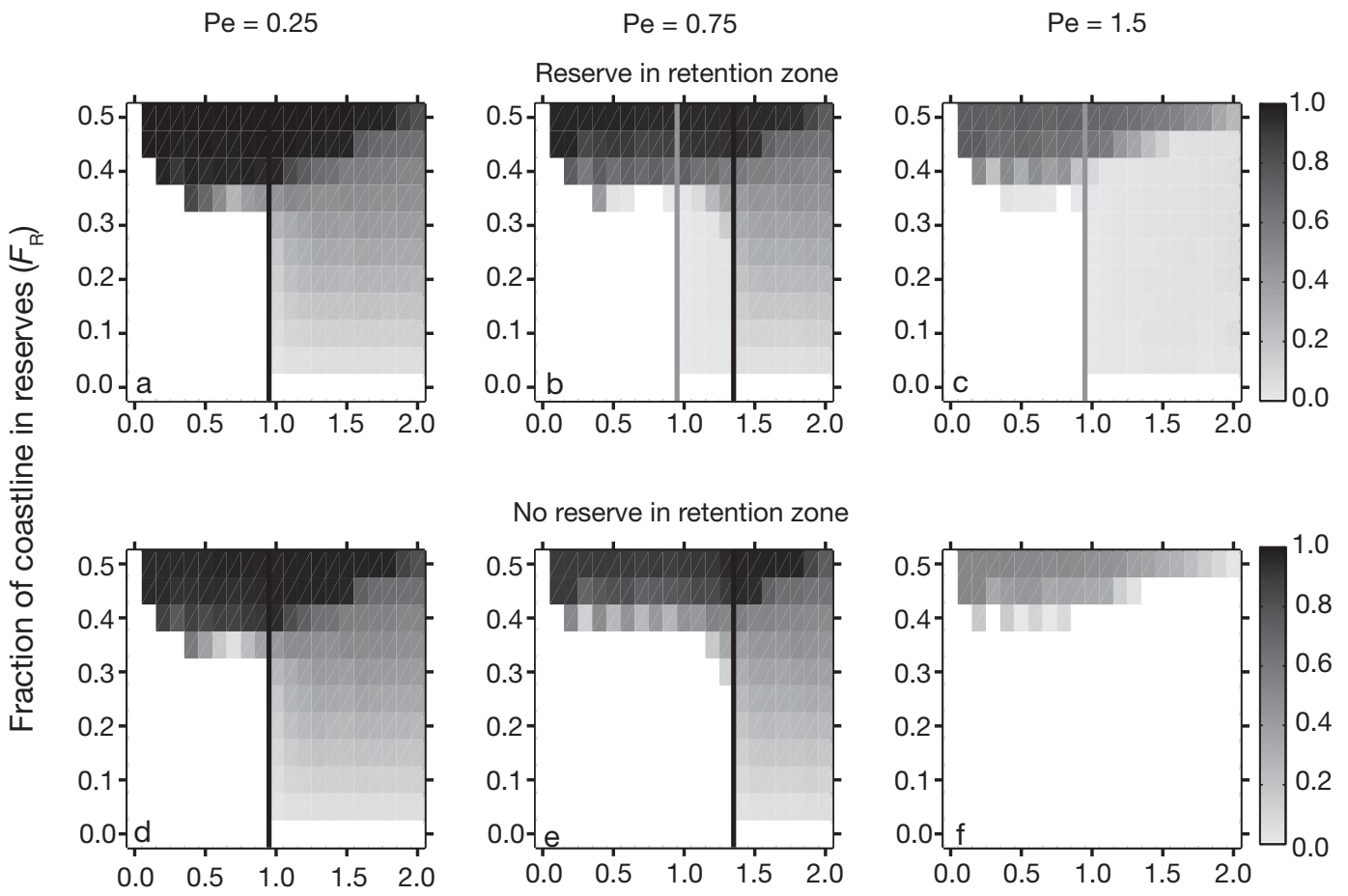

No reserve in retention zone
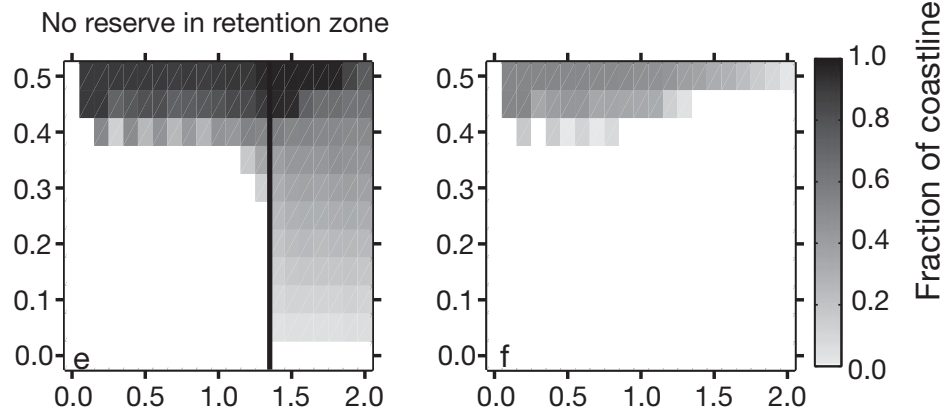

Reserve width $\left(R_{\mathrm{w}}\right.$; relative to $\left.L_{\mathrm{s}}\right)$

Fig. 7. Mean fraction of the coastline saturated with recruits under different reserve configurations for dispersal scenario B. Pixels: reserve network with a particular combination of $W_{\mathrm{R}}$ and $F_{\mathrm{R} i}$ pixel shading: recruit saturation at equilibrium; white areas: non-persistent metapopulations. In panels $\mathrm{a}-\mathrm{c}$, reserves are sited in retention zones; in $\mathrm{d}-\mathrm{f}$, they are not. Vertical lines: gray, minimum $W_{\mathrm{R}}$ for the reserves in the retention zones to be self-persistent; black, minimum $W_{\mathrm{R}}$ for all reserves to be self-persistent (in panel a, reserves inside and outside the retention zones have the same minimum width for self-persistence). Peclet number (Pe) was either $0.25(\mathrm{a}, \mathrm{d}), 0.75(\mathrm{~b}, \mathrm{e})$, or $1.5(\mathrm{c}, \mathrm{f})$. Larvae spawned inside the retention zone had same $L_{\mathrm{S}}$ as larvae spawned on the open coast but $L_{\mathrm{A}}=0$ (so Pe $=0$ ). In these model runs, CRT $=0.35$, FLEP $=1$ inside reserves, FLEP $=0$ outside reserves. See Table 1 for definitions

persistence to nearly $100 \%$ saturation in dispersal scenarios A and B (Figs. 6 \& 7). Because reserves were not wide enough to be self-persistent, this pattern represented network persistence. When reserves were wide enough to be self-persistent (regions to the right of the black line in Figs. 6 \& 7), increasing $F_{\mathrm{R}}$ produced a similar sudden jump to $100 \%$ recruit saturation, although this threshold fraction was generally higher because larger reserves were spaced further apart, reducing larval spillover from reserves to non-reserve areas (as in Fig. 4g,h).

In dispersal scenarios $\mathrm{A}$ and $\mathrm{B}$, higher values of $\mathrm{Pe}$ increased the minimum $W_{\mathrm{R}}$ necessary for self-persistence, but had no effect on the minimum $F_{\mathrm{R}}$ required for network persistence. As such, having reserves in the retention zones, where Pe was lower than on the open coast, typically lowered the minimum $W_{\mathrm{R}}$ necessary for self-persistence (and overall metapopulation persistence) but had no effect on the minimum $F_{\mathrm{R}}$ required for network persistence. For higher values of $\mathrm{Pe}$, the minimum $W_{\mathrm{R}}$ necessary for persistence was greater than the range of widths we considered (Figs. 6c,f \& 7c,f).
In scenario $\mathrm{C}$, the dispersal pattern was substantially different from that in the other 2 scenarios, and the resulting patterns of population persistence also differed somewhat (Fig. 8). It was still the case that persistence could be achieved by increasing either $W_{\mathrm{R}}$ or $F_{\mathrm{R}}$. When there were reserves in the retention zones, it was possible for those reserves to be self-persistent for small length scales of relaxation, $L_{\mathrm{R}}$ (Fig. 8a). As $L_{R}$ increased, less total larval supply arrived in the retention zones, so the reserves there were no longer selfpersistent and larger reserves were needed to persist at all (Fig. 8b). For small reserves, it was possible to achieve persistence via network effect with some minimum $F_{R}$, but there was not an immediate jump to $100 \%$ recruit saturation (as in scenarios $\mathrm{A}$ and $\mathrm{B}$ ) because larval supply was so unevenly distributed (Fig. 8a). When there were no reserves in the retention zones, there were no persistent metapopulations at all for low $L_{\mathrm{R}}$ because the vast majority of larvae settled inside the retention zones and not in the reserves (Fig. 8d). For slightly higher $L_{R}$, metapopulation persistence became possible but generally required larger reserves or a higher $F_{\mathrm{R}}$ than when reserves were in the 

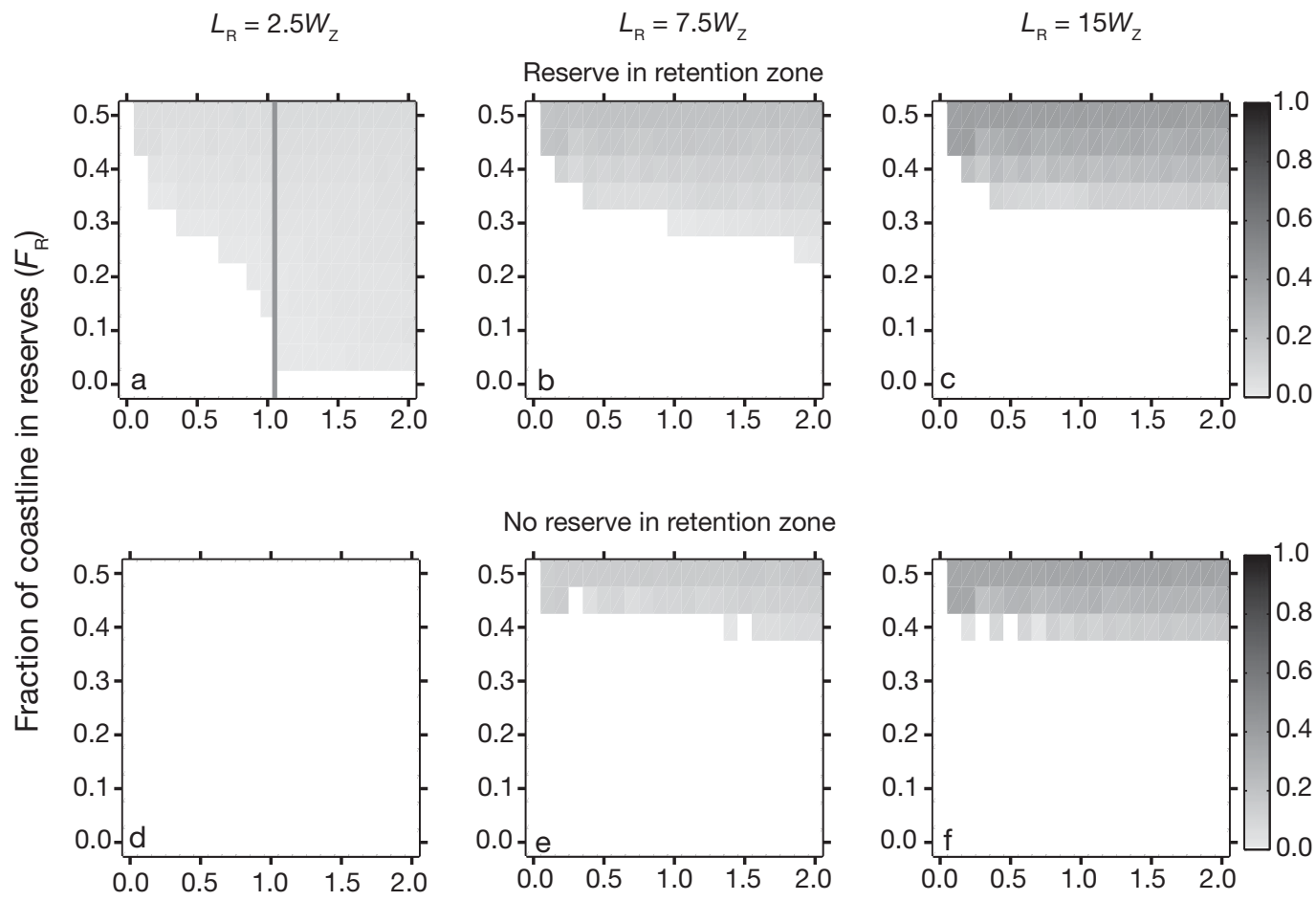

No reserve in retention zone
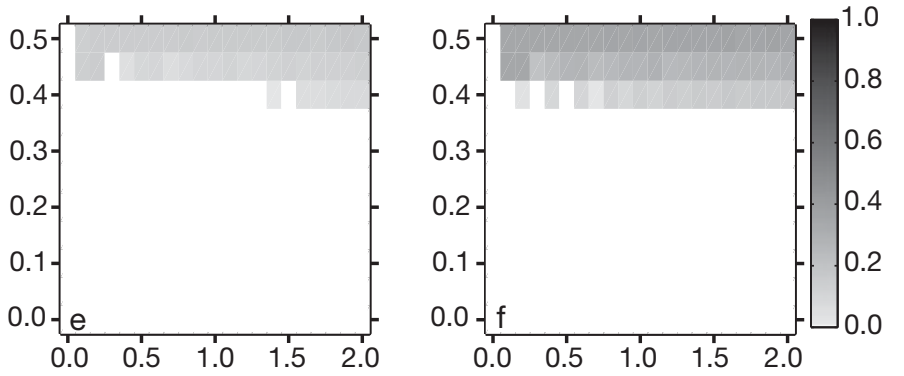

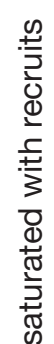

\section{Reserve width $\left(R_{\mathrm{w}}\right.$; relative to $\left.L_{\mathrm{s}}\right)$}

Fig. 8. Mean fraction of the coastline saturated with recruits under different reserve configurations for dispersal scenario C. Pixels: reserve network with a particular combination of $W_{\mathrm{R}}$ and $F_{\mathrm{R} i}$ pixel shading: recruit saturation at equilibrium; white areas: non-persistent metapopulations. In panels $\mathrm{a}-\mathrm{c}$, reserves are sited in retention zones; in $\mathrm{d}-\mathrm{f}$, they are not. Gray vertical line: see Fig. 6. The length scale of dispersal, $L_{\mathrm{R}}$, was either $2.5 W_{Z}(\mathrm{a}, \mathrm{d}), 7.5 W_{\mathrm{Z}}(\mathrm{b}, \mathrm{e})$ or $15 W_{\mathrm{Z}}(\mathrm{c}, \mathrm{f})\left(W_{\mathrm{Z}}\right.$ : width of the retention zone). In these model runs, $\mathrm{CRT}=0.35, \mathrm{FLEP}=1$ inside reserves, FLEP $=0$ outside reserves. See Table 1 for definitions

retention zones. Note that when $F_{\mathrm{R}}$ was sufficient to support a persistent metapopulation, recruit saturation actually increased with $L_{\mathrm{R}}$ because larvae were more evenly distributed along the coastline.

The results in Figs. 5 to 8 call attention to 2 key thresholds: the minimum $W_{\mathrm{R}}$ needed to sustain selfpersistent reserves and the minimum $F_{\mathrm{R}}$ needed to achieve network persistence. These thresholds are sensitive to both dispersal scenario and the length scale of dispersal (whether Pe or $L_{R i}$ Figs. 6 to 8). In addition, they are likely to be sensitive to the level of adult reproductive effort (determined by FLEP and CRT in our model) both inside and outside reserves (Botsford et al. 2001). To examine the joint effect of all of these factors on the 2 persistence thresholds, we determined the minimum $W_{\mathrm{R}}$ required for metapopulation persistence (given $F_{\mathrm{R}}=5 \%$ ) and the minimum $F_{\mathrm{R}}$ (given $W_{\mathrm{R}}=0.1 L_{\mathrm{S}}$ ) for a range of FLEP, CRT, and Pe values, for reserves in and out of the retention zones, and for each dispersal scenario (Figs. 9 \& 10).

We first consider variation in the reserve width threshold (Fig. 9). For dispersal scenario A, the minimum $W_{\mathrm{R}}$ increased with Pe in an accelerating manner (Fig. 9a,d). For Pe $>1$, the minimum $W_{\mathrm{R}}$ became ex- tremely large quite rapidly. The minimum $W_{\mathrm{R}}$ was always lower for higher values of FLEP (i.e. when there was more reproductive output in regions outside reserves; Fig. 9a) and for lower values of the CRT (i.e. when recruit survival at low population densities was higher; Fig. 9d). When FLEP > CRT, the metapopulation persisted without reserves, so the minimum $W_{\mathrm{R}}$ was zero (Fig. 9a). In every case, the metapopulation could persist with smaller reserves if there were reserves in the retention zones. The results for dispersal scenario B (Fig. 9b,e) were similar to those in scenario A, except that there was no effect of Pe on the minimum $W_{R}$ when reserves were in the retention zones. This occurred because $L_{\mathrm{A}}=0$ in the retention zones in scenario $B$, so the self-persistence of local populations inside the retention zone was determined only by $L_{\mathrm{S}}$, which did not vary with Pe. The results for dispersal scenario C (Fig. 9c,f) were quite different from the other 2 scenarios. Metapopulation persistence required larger reserves as $L_{R}$ increased, but the increase in minimum $W_{\mathrm{R}}$ was linear and very steep rather than exponentially increasing. Persistence was possible with smaller reserves for higher values of FLEP and lower values of the CRT (as in the other 2 

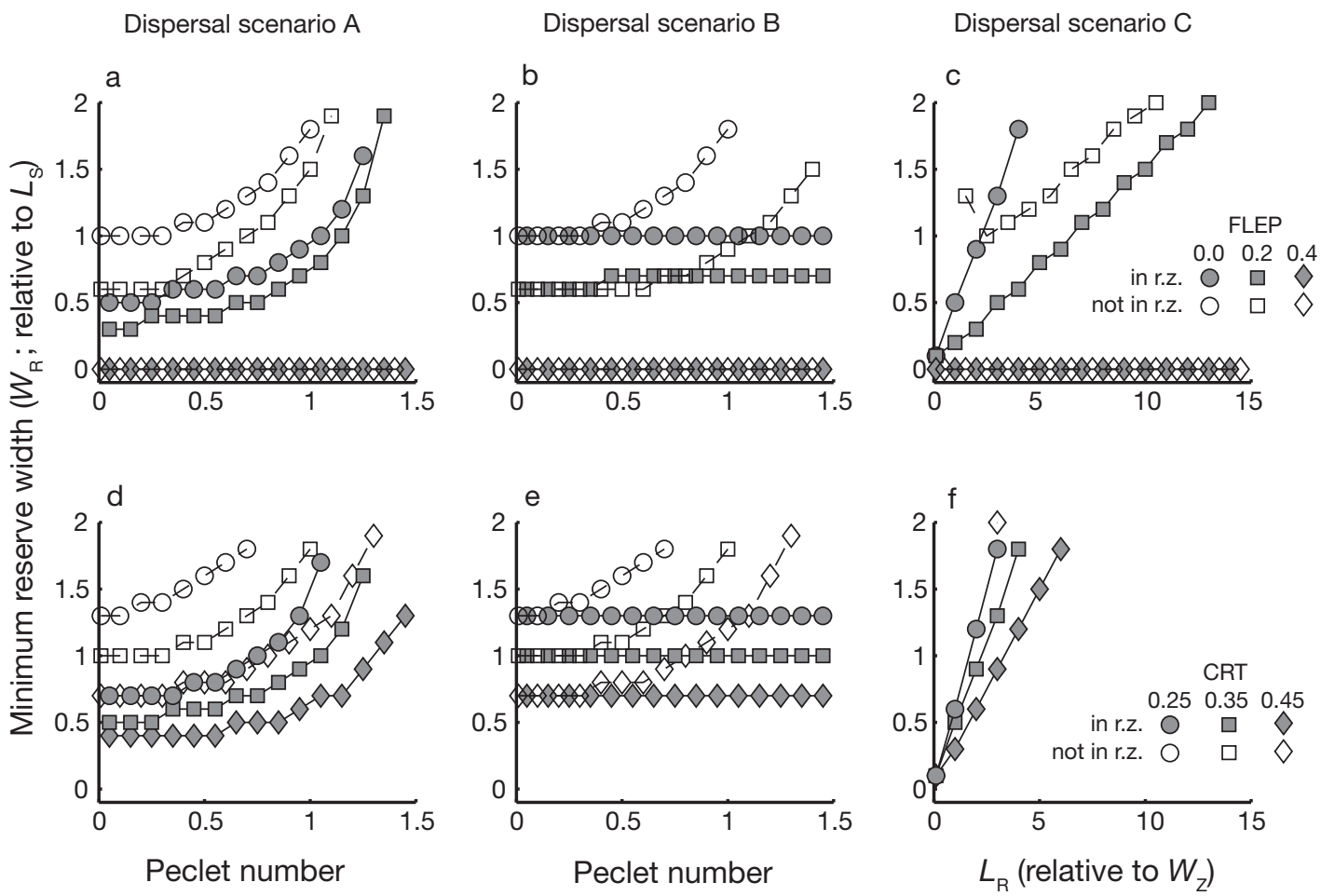

Fig. 9. Minimum reserve width required for population persistence with $5 \%$ of the coastline in reserves, as a function of Peclet number $(\mathrm{Pe})$ for dispersal scenarios $\mathrm{A}(\mathrm{a}, \mathrm{d})$ and $\mathrm{B}(\mathrm{b}, \mathrm{e})$ or as a function of dispersal length scale $\left(L_{\mathrm{R}}\right)$ for dispersal scenario $\mathrm{C}(\mathrm{c}, \mathrm{f})$. Model runs of reserves in both retention zones (r.z.) $(O, \square, \diamond)$ and nonretention zones $(O, \square, \diamond)$. $(\mathrm{a}-\mathrm{C}) \mathrm{CRT}=0.35, \mathrm{FLEP}=0,0.2$, or 0.4 outside reserves; $(\mathrm{d}-\mathrm{f}) \mathrm{FLEP}=0, \mathrm{CRT}=0.25,0.35$, or 0.45 . See Table 1 for definitions

scenarios), and required very large reserves if there were no reserves in the retention zones. The slight decrease in the minimum $W_{\mathrm{R}}$ with $L_{\mathrm{R}}$ when there were no reserves in retention zones (Fig. 9c) occurred because the initial increase in $L_{R}$ actually led to higher larval supply to reserves just upstream of the retention zone.

The patterns of variation in the minimum $F_{\mathrm{R}}$ needed for persistence (Fig. 10) were much simpler than those for the minimum $W_{\mathrm{R}}$. The minimum $F_{\mathrm{R}}$ decreased with increasing FLEP (Fig. 10a-c) and increased with increasing CRT (Fig. 10d-f) for all 3 dispersal scenarios, although the threshold converged on a single value for values of the CRT $>0.35$ (Fig. 10d-f). As with the minimum $R_{\mathrm{W}}$, the patterns were slightly different for dispersal scenario C. As $L_{\mathrm{R}}$ increased (making larval supply more evenly spread along the coastline), the results for scenario $C$ converged on the same values of minimum $F_{\mathrm{R}}$ obtained in scenarios $\mathrm{A}$ and $\mathrm{B}$, but the minimum $F_{\mathrm{R}}$ was initially very low when reserves were in the retention zones (because only a small reserve in the retention zone is necessary for persistence) and very high when there were no reserves in the retention zones (because overall larval production must be high to compensate for the relatively low larval delivery to reserves outside the retention zones). Aside from that detail, the minimum $F_{\mathrm{R}}$ necessary for metapopulation persistence was not sensitive to whether reserves were in the retention zones.

\section{DISCUSSION}

We examined how reserve performance could be affected by 3 basic types of dispersal heterogeneity that could be introduced by an oceanographic retention zone. These were localized reductions in both advective and stochastic dispersal length scales (scenario A), localized reductions in advective length scales only (scenario B), and uneven redistribution of larval supply from a well-mixed larval pool (scenario C). In a general sense, these stereotypical dispersal patterns simply describe the different ways in which some parts of a metapopulation might achieve higher rates of self-connectivity than others. In a practical sense, these scenarios represent the sort of limited information that might be available to reserve planners, i.e. they may have some general knowledge that flows are slower and/or recirculating in a particular location (Roberts et al. 2003, Hare \& Walsh 2007). By extending one-dimensional coastal metapopulation models to represent 
Dispersal scenario A

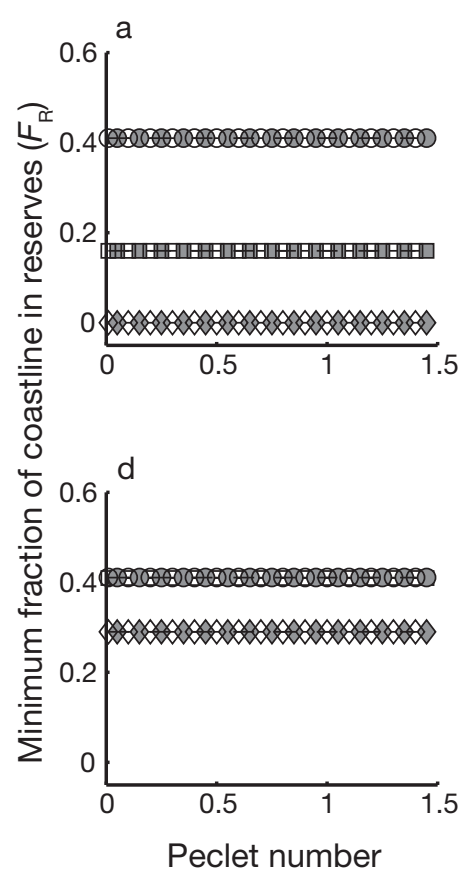

Dispersal scenario B
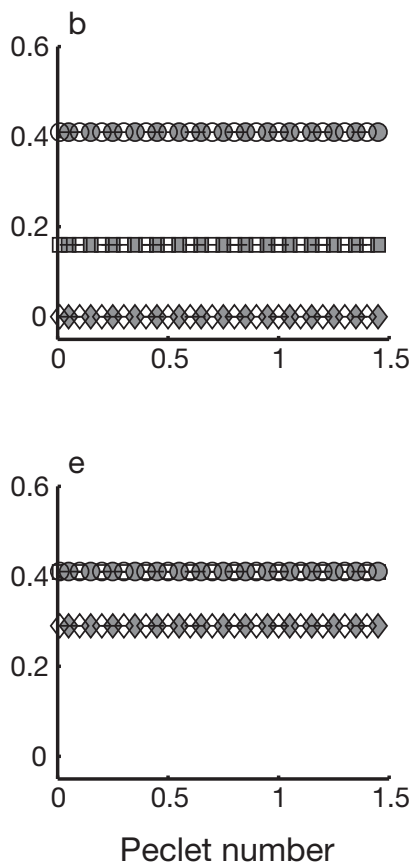

Dispersal scenario C
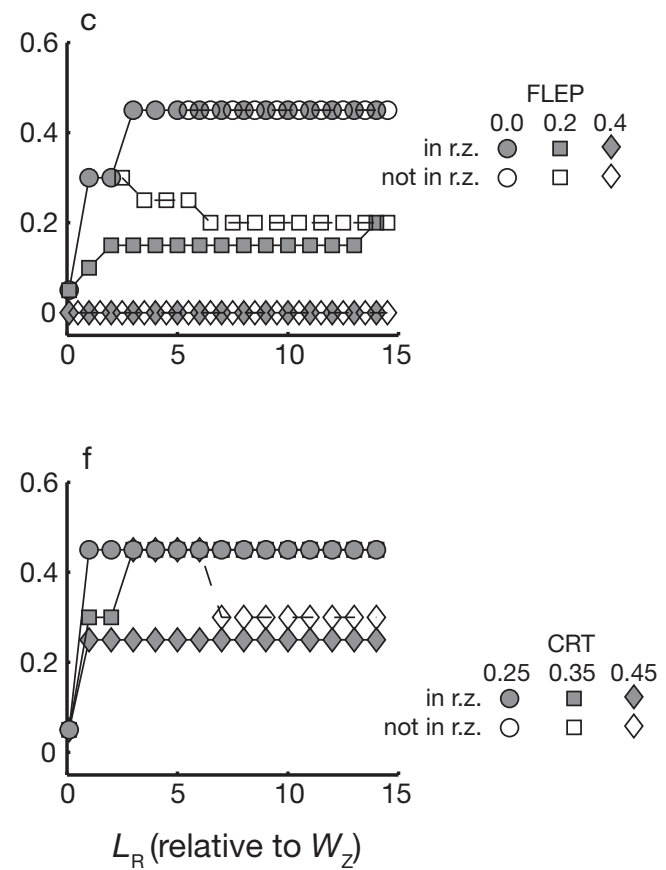

Fig. 10. Minimum fraction of the coastline in reserves required for population persistence with reserves of length $0.1 L_{\mathrm{S}}$ as a function of Peclet number (Pe) for dispersal scenarios A $(\mathrm{a}, \mathrm{d})$ and B (b e) or as a function of dispersal length scale $L_{\mathrm{R}}$ for dispersal scenario $C(\mathrm{c}, \mathrm{f})$. Model runs of reserves in both retention zones (r.z.) $(\mathrm{O}, \square, \diamond)$ and non retention zones $(\mathrm{O}, \square, \diamond) .(\mathrm{a}-\mathrm{C}) \mathrm{CRT}=0.35$, $\mathrm{FLEP}=0,0.2$, or 0.4 outside reserves; $(\mathrm{d}-\mathrm{f}) \mathrm{FLEP}=0, \mathrm{CRT}=0.25,0.35$, or 0.45 . See Table 1 for definitions

these 3 types of dispersal heterogeneities, we found 2 general results: First, placing reserves in retention zones reduced the minimum reserve size necessary to sustain a self-persistent local population. Second, placing reserves in the retention zone had no effect on the minimum fraction of the coastline that must be in reserves to sustain a metapopulation via a network effect in the absence of selfpersistent reserves.

In all 3 dispersal scenarios, high rates of selfconnectivity allowed single small reserves to persist in retention zones where most larvae were locally retained and could replenish the adult population in that reserve. However, self-persistence was not always limited to the retention zone: as reserve size increased in scenarios A and B, all of the reserves in the network became self-persistent. In such cases, each reserve could exist in isolation without reproductive input from its neighbors. However, self-persistence is only sufficient, not necessary, for persistence of the entire population. At the opposite extreme were networks with no self-persistent reserves, maintained solely by network connectivity. In our models, this occurred when individual reserves were small but a large fraction of the coastline was in reserves, allowing substantial connectivity between neighbors (in scenarios A and B) and/or a sufficient area for larval production (especially important in scenario C).

In all cases, persistence was possible with smaller and fewer reserves if the CRT was lower because lower CRT corresponds to high per-capita survival of individual recruits at low density, so that lower rates of larval supply are required for population replacement. Metapopulation persistence was also possible with smaller and fewer reserves when the FLEP was higher outside of reserves, although this did not affect the minimum $W_{\mathrm{R}}$ necessary for self-persistence (which is determined only by reproduction and connectivity within the reserve, not outside it). In the extreme, reserves were not necessary for persistence if FLEP exceeded the CRT.

The relationship between the length scales of dispersal and metapopulation persistence differed among the 3 dispersal scenarios. For the 2 scenarios (A and B) with a dispersal kernel localized near the spawning location, increasing the Pe greatly increased the minimum $W_{\mathrm{R}}$ necessary for persistence. This result matches those from studies of population persistence in homogeneous advective flows: total reproductive output at a location (here equivalent to the size of the reserve) must increase nonlinearly 
with the strength of advection in order to maintain a persistent population (Lutscher et al. 2005, Pachepsky et al. 2005, Byers \& Pringle 2006). The persistence threshold was always easier to meet for reserves in the retention zone, where the advective component of the dispersal kernel was reduced (scenario A) or absent (scenario B). In scenario $\mathrm{C}$, the minimum $W_{\mathrm{R}}$ increased linearly with the length scale of dispersal for reserves in the retention zone. This occurred because increases in the dispersal length scale directed more of the total larval supply away from the retention zone, necessitating a larger reserve there (and thus increased larval production) to compensate. The minimum $W_{\mathrm{R}}$ was generally much greater when reserves were not in the retention zone, with the small exception that when the dispersal length scale was very small, slight increases in the length scale actually increased larval supply to the reserve adjacent to the retention zone. Unfortunately, we know of no analytical results to which to compare the simulation results because this type of dispersal scenario has not been widely modeled.

Interestingly, the length scales of dispersal had essentially no effect on the minimum fraction of the coastline that had to be in reserves to produce network persistence. This somewhat unexpected result reveals that even if advection is too strong for a single reserve to be self-persistent, the entire coastal metapopulation can persist if there are sufficient replacement paths (i.e. reserve area) and sufficient retention within the entire metapopulation (cf. Gaines et al. 2003, Lutscher et al. 2005). Because persistence in this case depends on the total larval output of the entire metapopulation, whether the reserves were located in the retention zone did not affect the persistence threshold. We caution that this result holds only for the range of dispersal length scales we considered. It is inevitable that for very high Peclet numbers, a coastline consisting entirely of reserves would not persist. It is also likely that this threshold would be lower for species with higher CRT (Byers \& Pringle 2006).

The different patterns of persistence we identified could lead to different outcomes in systems subject to occasional disturbances, although we are cautious in drawing inferences about stochastic systems from deterministic models. Multiple self-persistent reserves could provide redundancy to the network in the face of localized catastrophes (Allison et al. 2003): the extinction of a single patch would not necessarily threaten population-wide persistence, and recolonization from neighboring patches may be possible. By contrast, systems in which persistence arises from network connectivity may be especially sensitive to stochastic disturbance. In these cases, a localized extinction in a single reserve might disrupt network connectivity and lead to extinction of the entire population. However, network persistence may be crucial for intermediate- and longrange dispersers when it is not possible to place a reserve in an area of high self-connectivity, because it then becomes difficult to create a single reserve large enough to be self-persistent in the face of strong advective currents (see Figs. 6d \& 7d, also Gaines et al. 2003).

The source-sink concept has figured prominently in the development of marine reserve theory. Selfpersistence is a key element of this framework, as most authors include self-persistence among the qualities that define a source (Crowder et al. 2000, Tuck \& Possingham 2000, Roberts et al. 2003, Crowder \& Figueira 2006). However, networks of reserves may persist without a single self-persistent ('source') reserve; indeed, nearly the entire coastline may be saturated with recruits in such cases (e.g. left-hand side of Fig. 6d). By contrast, single small reserves may be selfpersistent (and thus sources under some definitions, Armsworth 2002) but have widely varying abilities to replenish other parts of the population (quite limited in the scenarios A and B, but quite high in scenario $\mathrm{C}$ ). These considerations reveal that it is the degree of replenishment through all connectivity paths, not just self-connectivity, that determines persistence and the spatial distribution of individuals in a metapopulation or reserve network (Hastings \& Botsford 2006). As such, it may be necessary to expand the traditional source-sink framework to include a network-based perspective on metapopulation dynamics. For example, Figueira \& Crowder (2006) proposed a metric for the contribution of a patch to the metapopulation that is analogous to the traditional source-sink framework of Pulliam (1988) but which accounts for the importance of connectivity pathways among patches. Their work (Crowder et al. 2000, Crowder \& Figueira 2006, Figueira \& Crowder 2006) and the results presented here suggest that both self-persistence and the potential for network connectivity should be used to determine conservation priorities. This general point extends beyond the context of marine reserves: although we described heterogeneity in post-settlement demography in terms of reserves and fished areas, similar results could be obtained if one modeled a system with benthic habitats of varying quality (Crowder et al. 2000, Crowder \& Figueira 2006).

In persistent networks with few reserves (i.e. a small $F_{\mathrm{R}}$ ), it was often the case that recruitment reached saturating densities only in the portion of the coastline within self-persistent reserves. As additional reserve area was added, the proportion of coastline saturated with recruits approached $100 \%$. However, the manner in which additional reserve area translated into additional habitat saturation (i.e. the marginal benefit of adding reserves) varied greatly with dispersal mode. 
For scenarios A and B, there was a tipping point associated with increases in reserve area: once more than a certain fraction of the coastline was in reserves (determined by adult reproductive output, see Fig. 10), the entire habitat became saturated with recruits. This effect was most pronounced when reserves were too small to persist on their own. As a consequence, protecting a large fraction of the coastline might yield no more benefit than protecting an amount closer to the persistence threshold (worse, actually, in terms of shrinking the area available for fishing outside reserves). By contrast, there was no such tipping point if larvae were well mixed before being redistributed, as in scenario $\mathrm{C}$. In that scenario, protecting additional habitat always led to additional gains in the proportion of the coastline saturated with recruits.

The models that have been used to generate guidelines for marine reserve placement have all considered a single species with a particular dispersal pattern (reviewed by Gerber et al. 2003), while, in practice, reserves are intended to protect diverse assemblages of species with a variety of dispersal patterns. Fortunately, our results suggest some general guidelines that hold for all 3 dispersal scenarios we considered. If it is only possible to implement a small number of reserves, population persistence will be best served by placing a reserve in an area of larval retention. If, however, it is undesirable to protect the retention zone (e.g. for political or socioeconomic reasons, or because toxins or pollutants are concentrated there; Largier 2004), it is still possible to achieve persistence by using larger reserves or protecting a larger area of the coastline (ideally a fraction of the coastline greater than the persistence threshold). Of course, species may exhibit quite different responses to the addition of marine reserves (note the disparity in response to a doubling of $W_{\mathrm{R}}$ in Fig. 4), a possibility that should be taken into account by those planning reserves and weighing the costs of additional reserve area, as well as by those examining reserves after implementation to quantify reserve benefits (Halpern \& Warner 2002).

By necessity, our modeling approach ignored several potential complexities that would affect the placement of actual reserves. In particular, habitat heterogeneity may enter the system in unexpected ways, such that areas with high larval retention have poor habitat, poor larval production, and are thus unsuitable as reserves (e.g. Lipcius et al. 2001). It is also possible that trophic interactions among species in reserves could introduce additional heterogeneity in demographic rates (Baskett et al. 2006, White 2008). Nonetheless, the results presented here provide some basic guidelines for the incorporation of dispersal heterogeneity into the design of marine reserves and the theory of marine metapopulations.
Acknowledgements. We thank S. Morgan for helpful discussions and 3 anonymous reviewers for comments that greatly improved the manuscript. Funding was provided by the NSF Coastal Ocean Processes (CoOP) program, Wind Events and Shelf Transport project (OCE-9910897). This publication is a contribution of the Bodega Marine Laboratory, University of California at Davis.

\section{LITERATURE CITED}

Aiken CM, Navarrete SA, Castillo MI, Castilla JC (2007) Along-shore larval dispersal kernels in a numerical ocean model of the central Chilean coast. Mar Ecol Prog Ser 339: $13-24$

Allison GW, Gaines SD, Lubchenco J, Possingham HP (2003) Ensuring persistence of marine reserves: catastrophes require adopting an insurance factor. Ecol Appl 13: $\mathrm{S} 8-\mathrm{S} 24$

Almany GR, Berumen ML, Thorrold SR, Planes S, Jones GP (2007) Local replenishment of coral reef fish populations in a marine reserve. Science 316:742-744

Armsworth PR (2002) Recruitment limitation, population regulation, and larval connectivity in reef fish metapopulations. Ecology 83:1092-1104

Barrowman NJ, Myers RA (2000) Still more spawnerrecruitment curves: the hockey stick and its generalizations. Can J Fish Aquat Sci 57:665-676

Baskett ML, Yoklavich M, Love MS (2006) Predation, competition, and the recovery of overexploited fish stocks in marine reserves. Can J Fish Aquat Sci 63:1214-1229

> Bode M, Bode L, Armsworth PR (2006) Larval dispersal reveals regional sources and sinks in the Great Barrier Reef. Mar Ecol Prog Ser 308:17-25

Botsford LW (2001) Physical influences on recruitment to California Current invertebrate populations on multiple scales. ICES J Mar Sci 58:1081-1091

Botsford LW, Hastings A, Gaines SD (2001) Dependence of sustainability on the configuration of marine reserves and larval dispersal distance. Ecol Lett 4:144-150

$>$ Botsford LW, White JW, Coffroth MA, Paris C and others (2009) Connectivity and resilience of coral reef metapopulations in MPAs: matching empirical efforts to predictive needs. Coral Reefs 28:327-337

Byers JE, Pringle JM (2006) Going against the flow: retention, range limits and invasions in advective environments. Mar Ecol Prog Ser 313:27-41

> Caley MJ, Carr MH, Hixon MA, Hughes TP, Jones GP, Menge BA (1996) Recruitment and the local dynamics of open marine populations. Annu Rev Ecol Syst 27:477-500

California Department of Fish and Game (CDFG) (2008) California marine life protection act master plan for marine protected areas, available at www.dfg.ca.gov/ mlpa/masterplan.asp. Accessed 4/4/2008

- Carr MH, Reed DC (1993) Conceptual issues relevant to marine harvest refuges: examples from temperate reef fishes. Can J Fish Aquat Sci 50:2019-2027

Caswell H (2001) Matrix population models: construction, analysis, and interpretation, 2nd edn. Sinauer Associates, Sunderland, MA

> Cowen RK, Paris CB, Srinivasan A (2006) Scaling of connectivity in marine populations. Science 311:522-527

Crowder LB, Figueira WF (2006) Metapopulation ecology and marine conservation. In: Kritzer JP, Sale PF (eds) Marine metapopulations. Academic Press, Burlington, MA, p 491-516

Crowder LB, Lyman SJ, Figueira WF, Priddy J (2000) Source- 
sink population dynamics and the problem of siting marine reserves. Bull Mar Sci 66:799-820

Diehl JM, Toonen RJ, Botsford LW (2007) Spatial variability of recruitment in the sand crab Emerita analoga throughout California in relation to wind-driven currents. Mar Ecol Prog Ser 350:1-17

Dorn MW (2002) Advice on West Coast rockfish harvest rates from Bayesian meta-analysis of stock-recruit relationships. N Am J Fish Manag 22:280-300

Gaines SD, Gaylord B, Largier JL (2003) Avoiding current oversights in marine reserve design. Ecol Appl 13:S32-S46

Gaines SD, Gaylord B, Gerber LR, Hastings A, Kinlan BP (2007) Connecting places: the ecological consequences of dispersal in the sea. Oceanography (Wash DC) 20:90-99

Gerber LR, Botsford LW, Hastings A, Possingham HP, Gaines SD, Palumbi SR, Andelman S (2003) Population models for marine reserve design: a retrospective and prospective synthesis. Ecol Appl 13:S47-S64

Gilg MR, Hilbish TJ (2003) The geography of marine larval dispersal: coupling genetics with fine-scale physical oceanography. Ecology 84:2989-2998

Goodyear CP (1993) Spawning stock biomass per recruit in fisheries management: foundation and current use. Publ Spec Can Sci Halieut Aquat 120:67-81

> Graham WM, Largier JL (1997) Upwelling shadows as nearshore retention sites: the example of northern Monterey Bay. Cont Shelf Res 17:509-532

> Halpern BS, Warner RR (2002) Marine reserves have rapid and lasting effects. Ecol Lett 5:361-366

> Halpern BS, Warner RR (2003) Matching marine reserve design to reserve objectives. Proc Biol Sci 270:1871-1878

> Hare JA, Walsh HJ (2007) Planktonic linkages among marine protected areas on the south Florida and southeast United States continental shelves. Can J Fish Aquat Sci 64: $1234-1247$

> Hastings A, Botsford LW (2003) Comparing designs of marine reserves for fisheries and for biodiversity. Ecol Appl 13: S65-S70

> Hastings A, Botsford LW (2006) Persistence of spatial populations depends on returning home. Proc Natl Acad Sci USA 103:6067-6072

James MK, Armsworth PR, Mason LB, Bode L (2002) The structure of reef fish metapopulations: modelling larval dispersal and retention patterns. Proc Biol Sci 269: 2079-2086

Kaplan DM (2006) Alongshore advection and marine reserves: consequences for modeling and management. Mar Ecol Prog Ser 309:11-24

Kaplan DM, Largier J (2006) HF radar-derived origin and destination of surface waters off Bodega Bay, California. Deep-Sea Res II 53:2906-2930

Kaplan DM, Largier J, Botsford LW (2005) HF radar observations of surface circulation off Bodega Bay (northern California, USA). J Geophys Res 110, C10020, doi:10.1029/ 2005JC002959

Kaplan DM, Botsford LW, Jorgensen S (2006) Dispersal per recruit: an efficient method for assessing sustainability in marine reserve networks. Ecol Appl 16:2248-2263

Kaplan DM, Botsford LW, O'Farrell MR, Gaines SD, Jorgenson S (2009) Model-based assessment of persistence in proposed marine protected area designs. Ecol Appl 19: 433-448

Largier JL (2004) The importance of retention zones in the dispersal of larvae. Am Fish Soc Symp 42:105-122

Largier JL (2003) Considerations in estimating larval dispersal distances from oceanographic data. Ecol Appl 13: S71-S89
Largier JL, Magnell BA, Winant CD (1993) Subtidal circulation over the northern California shelf. J Geophys Res 98: $18147-18179$

> Largier JL, Lawrence CA, Roughan M, Kaplan DM and others (2006) WEST: a northern California study of the role of wind-driven transport in the productivity of coastal plankton communities. Deep-Sea Res II 53:2833-2849

Levin LA (2006) Recent progress in understanding larval dispersal: new directions and digressions. Integr Comp Biol 46:282-297

> Lipcius RN, Stockhausen WT, Eggleston DB (2001) Marine reserves for Caribbean spiny lobster: empirical evaluation and theoretical metapopulation recruitment dynamics. Mar Freshw Res 52:1589-1598

Lutscher F, Pachepsky E, Lewis MA (2005) The effect of dispersal patterns on stream populations. SIAM J Appl Math 65:1305-1327

Mace AJ, Morgan SG (2006) Larval accumulation in the lee of a small headland: implications for the design of marine reserves. Mar Ecol Prog Ser 318:19-29

Mace PM, Sissenwine MP (1993) How much spawning per recruit is enough? Publ Spec Can Sci Halieut Aquat 120: 101-118

Miller JA, Banks MA, Gomez-Uchida D, Shanks AL (2005) A comparison of population structure in black rockfish (Sebastes melanops) as determined with otolith microchemistry and microsatellite DNA. Can J Fish Aquat Sci 62:2189-2198

Moffitt EA, Botsford LW, Kapla DM, O'Farrell MR (2009) Marine reserve networks for species that move within a home range. Ecol Appl 19:1835-1847

> Nelson G, Hutchings L (1983) The Benguela upwelling area. Prog Oceanogr 12:333-356

> Neubert MG (2003) Marine reserves and optimal harvesting. Ecol Lett 6:843-849

Pachepsky E, Lutscher F, Nisbet RM, Lewis MA (2005) Persistence, spread and the drift paradox. Theor Popul Biol 67: $61-73$

> Penven P, Roy C, Colin de Verdière A, Largier J (2000) Simulation of a coastal jet retention process using a barotropic model. Oceanol Acta 23:615-634

Petersen CH, Drake PT, Edwards CA, Ralston S (2010) A numerical study of inferred rockfish (Sebastes spp.) larval dispersal along the central California coast. Fish Oceanogr 19:21-41

Pineda J, Hare JA, Sponaugle S (2007) Larval transport and dispersal in the coastal ocean: consequences for population connectivity. Oceanography (Wash DC) 20:22-39

Quinn JF, Hastings A (1987) Extinction in subdivided habitats. Conserv Biol 1:198-208

Roberts CM, Andelman S, Branch G, Bustamante RH and others (2003) Ecological criteria for evaluating candidate sites for marine reserves. Ecol Appl 13:S199-S214

Roughan MA, Mace J, Largier JL, Morgan SG, Fisher JL, Carter ML (2005) Subsurface recirculation and larval retention in the lee of a small headland: a variation on the upwelling shadow theme. J Geophys Res 110, C10027, doi:10.1029/2005JC002898

Sale PF, Hanski I, Kritzer JP (2006) The merging of metapopulation theory and marine ecology: establishing the historical context. In: Kritzer JP, Sale PF (eds) Marine metapopulations. Elsevier Academic Press, Burlington, MA, p 3-30

> Shanks AL, Eckert GL (2005) Population persistence of California Current fishes and benthic crustaceans: a marine drift paradox. Ecol Monogr 75:505-524

Shanks AL, Grantham BA, Carr MH (2003) Propagule disper- 
sal distance and the size and spacing of marine reserves. Ecol Appl 13:S159-S169

Siegel DA, Kinlan BP, Gaylord B, Gaines SD (2003) Lagrangian descriptions of marine larval dispersion. Mar Ecol Prog Ser 260:83-96

Siegel DA, Mitarai S, Costello CJ, Gaines SD, Kendall BE, Warner RR, Winters KB (2008) The stochastic nature of larval connectivity among nearshore marine populations. Proc Natl Acad Sci USA 105:8974-8979

Sissenwine MP, Shepherd JG (1987) An alternative perspective on recruitment overfishing and biological reference points. Can J Fish Aquat Sci 44:913-918

Strub PT, Mesías JM, Montecinos V, Rutlland J, Salinas S (1998) Coastal ocean circulation off western South America. In: Robinson AR, Brink KH, (eds) The sea. J Wiley \& Sons, New York, NY, p 273-313

Tuck GN, Possingham HP (2000) Marine protected areas for spatially structured exploited stocks. Mar Ecol Prog Ser 192:89-101

Van Kirk RW, Lewis MA (1997) Integrodifference models for persistence in fragmented habitats. Bull Math Biol 59: 107-137

Walters CJ, Hilborn R, Parrish R (2007) An equilibrium model for predicting the efficacy of marine protected

Editorial responsibility: Romuald Lipcius,

Gloucester Point, Virginia, USA areas in coastal environments. Can J Fish Aquat Sci 64: 1009-1018

Werner FE, Cowen RK, Paris CB (2007) Coupled biological and physical models: present capabilities and necessary developments for future studies population connectivity. Oceanography (Wash DC) 20:54-68

White JW (2008) Spatially coupled larval supply of marine predators and their prey alters the predictions of metapopulation models. Am Nat 171:E179-E194

Wing SR, Botsford LW, Largier JL, Morgan LE (1995a) Spatial structure of relaxation events and crab settlement in the northern California upwelling system. Mar Ecol Prog Ser 128:199-211

Wing SR, Largier JL, Botsford LW, Quinn JF (1995b) Settlement and transport of benthic invertebrates in an intermittent upwelling region. Limnol Oceanogr 40:316-329

Wing SR, Botsford LW, Ralston SV, Largier JL (1998) Meroplanktonic distribution and circulation in a coastal retention zone of the northern California upwelling system. Limnol Oceanogr 43:1710-1721

Wing SR, Botsford LW, Morgan LE, Diehl JM, Lundquist CJ (2003) Inter-annual variability in larval supply to populations of three invertebrate taxa in the northern California Current. Estuar Coast Shelf Sci 57:859-872

Submitted: July 7, 2008; Accepted: September 17, 2009 Proofs received from author(s): December 22, 2009 